\title{
SEISMIC BASE ISOLATION IN STRENGTHENING FRAME STRUCTURE OF MIDDLE SCHOOL TEACHING BUILDING IN ZHUONI- CHINA
}

\author{
Qasem Riyadh Ghaleb Abdulwahab ${ }^{1}$, Sun Jianqin², Qi Jie ${ }^{3}$ \\ ${ }^{1}$ MSc. Structural Engineering Student, Lanzhou Jiaotong University, Lanzhou, China \\ ${ }^{2}$ Professors, Lanzhou Jiaotong University, Lanzhou, China \\ ${ }^{3}$ MSc. Structural Engineering Student, Lanzhou Jiaotong University, Lanzhou, China
}

\begin{abstract}
Seismic isolation is a technique that has been used around the world to protect building structures, nonstructural components and content from the damaging effects of earthquake ground shaking. In this paper, frame structure concrete of middle school teaching building, the project from Zhuoni County Middle School Center of the Gannan city is located in the southeast part of Gansu province in China. The frame structure used PKPM software in the design and Sap2000 was used to remodel the structure, analyze and then applied the seismic base isolation. This teaching building has been strengthened to be fortified against ultimate bearing capacity failure as it is an existing structure. The lead rubber bearing, Isolators, LRB400, NRB400 and LRB500, the modal and time history analysis of isolated structure and non isolated structure were carried out, and the analysis results of two structures were being compared. The results show that the natural vibration period of the structure can be effectively prolonged and the shear forces and displacement between layers can be reduced effectively after the structural isolation bearings are arranged. Analysis and comparison of the isolated structure and non isolated structure of their shear forces, acceleration and displacement seismic, found that isolation structure can significantly reduce the shear forces and acceleration and increased displacement. Structure's of Seismic response improves the structure seismic fortification level, which proves that the shock absorption effect is good.
\end{abstract}

Keywords: Frame structure; Isolation structure; Lead rubber bearing; and Time history analysis. $* * *$

\section{INTRODUCTION}

The school is to bear the national future students with life and the live safety of the students maintain national security issues in the future. Middle school buildings crowded with flow volume, frequent activities, teaching and living facilities affiliated are relatively concentrated, and the average age of the students is low, weak sense of the self-protection and self rescue ability, once the earthquake, the possibility and harmfulness of secondary disasters than other types of construction much caused by earthquake disaster and pressure [1]. In recent years after the 2008 Wen Chuan earthquake, domestic scholars on the basis of continuous research have developed new methods and other seismic measures including the isolation technology geared at improving the seismic capacity of structures. This isolation technology which is widely recognized by Chinese scholars can greatly reduce the seismic response of the upper structure, so as to reduce the structural damage. In the current structure seismic technology, isolation technology is the theoretical system of the most perfect, the most practical application and has been successfully tested through structural seismic control technology [2]. Base isolation concept was coined by engineers and scientists as early as in the 1923 and thereafter different methods of isolating the buildings and structures from earthquake forces have been developed world over. Countries like US, New Zealand, Japan, China and European countries have adopted these techniques as their normal routine for many public buildings and residential buildings as well[3]. Japan's first isolated building was built in 1921 at the Tokyo Royalist Hotel, the foundations of the building had hard concrete of 2-4 meters thick, a soft soil layer thickness of $18-21 \mathrm{~m}$, at that time the design method of this kind has aroused great concern and discussion [4]. In 2004, Lu Xilin made a performance of the experiment and Research on the combined isolation system, analysis of the impact of ground motion on the upper structure and isolation system; his experiments show that the unidirectional and bidirectional earthquake action has little effect when considering the vertical earthquake effect is remarkable [5]. In china, the most commonly used isolation systems are the seismic base isolation elastomeric isolator: lead rubber bearings (LRB); Natural rubber bearings (NRB); and high rubber bearings (HRB); and the sliding isolator: resilient friction system; and friction pendulum system. With the base isolators, the entire structure is divided into three parts, namely; the superstructure, the base isolation layer and the foundation. It is impossible to completely separate the superstructure from the 
substructure as in most buildings, for they were constructed in-situ and as a monolithic structure, especially with respect to their connection joints [8].

\section{MODEL DEVELOPMENT}

\subsection{The Mode of Structure}

This project from Zhuoni County Middle School Center of the Gannan city is located in the southeast part of Gansu province. The middle school is a $34.60 \mathrm{~m} \mathrm{X} 10 \mathrm{~m}$ building and of height $14.7 \mathrm{~m}$, first storey, second storey is a $3.60 \mathrm{~m}$, third storey $3.90 \mathrm{~m}$ and four storey $3.30 \mathrm{~m}$ as shown in figures 1 and 2.There have been many occurrences of small earthquakes according to the Lanzhou seismic station records of the Nin County and Zhuoni County, earthquake magnitudes of 5.2 and 5.0 were recorded in 2003 and 2004 respectively. In the early 1987 however, earthquake magnitudes of 5.9 and 5.1 were recorded in the Gansu province[6]. Seismic fortification and building type: according to the code for 《seismic design of buildings in Gansu province of China 》 DB62/T25-30552011. The seismic precautionary intensity for Gannan city is a level 7 and that for Zhuoni County is a level 8. The basic earthquake acceleration of the land is $0.20 \mathrm{~g}$; maximum design acceleration of $0.16 \mathrm{~g}$ was used for the structure. The earthquake design is a group 3 type with design seismic building category 2 or $\mathrm{C}$ class and the land category II. The site classification is a group 2 type and the characteristic is $0.45 \mathrm{~s}$. The structural damping ratio is $1: 20(5 \%)$, the influence coefficient of the most frequently encountered earthquake is 0.08 , and the maximum impact coefficient of the rare earthquake is 0.50 .

\subsection{The Mode Design}

Chinese PKPM software was used for the structural design while SAP200 was used for the structure analysis.

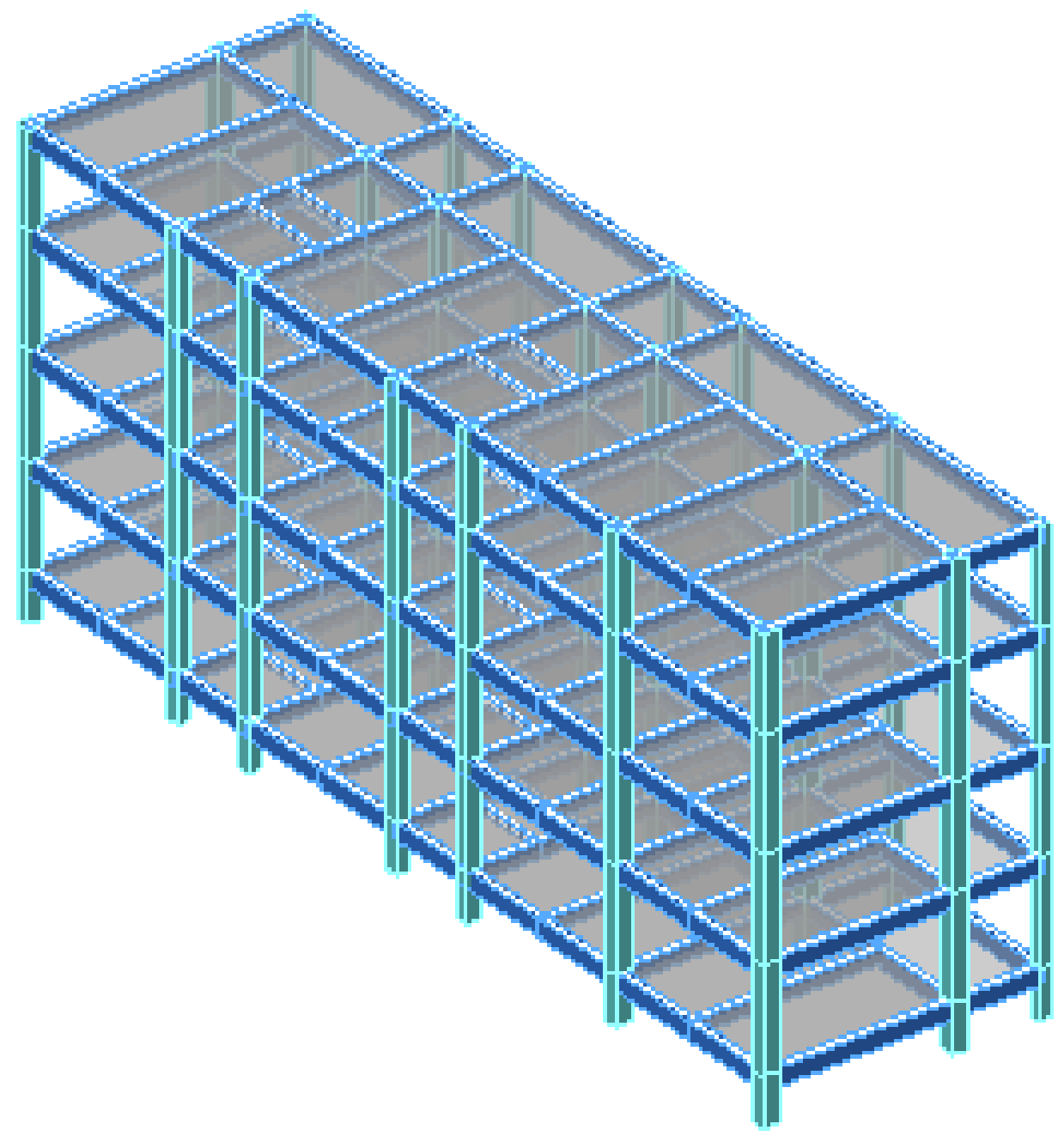

Fig 1: PKPM Structural Model 


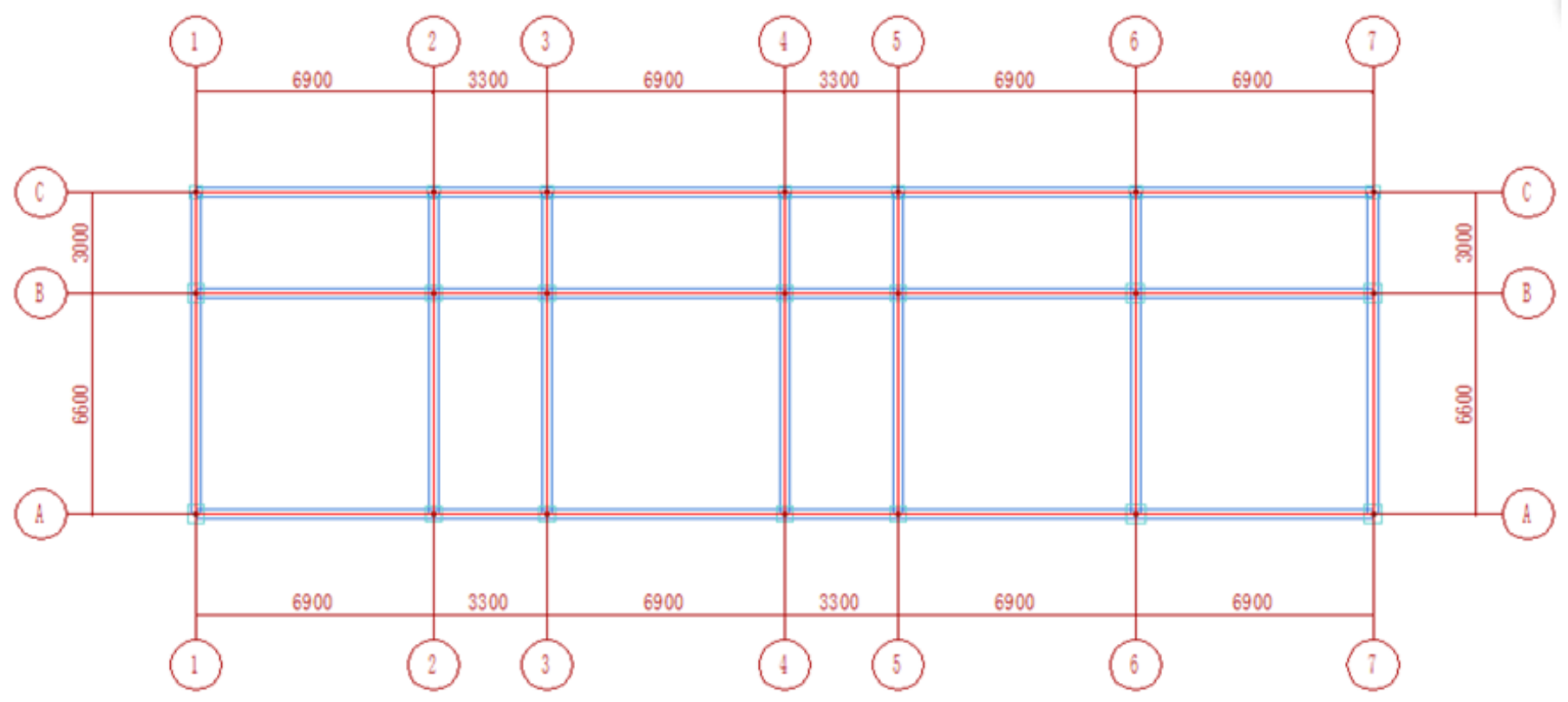

Fig 2: Structural Plan

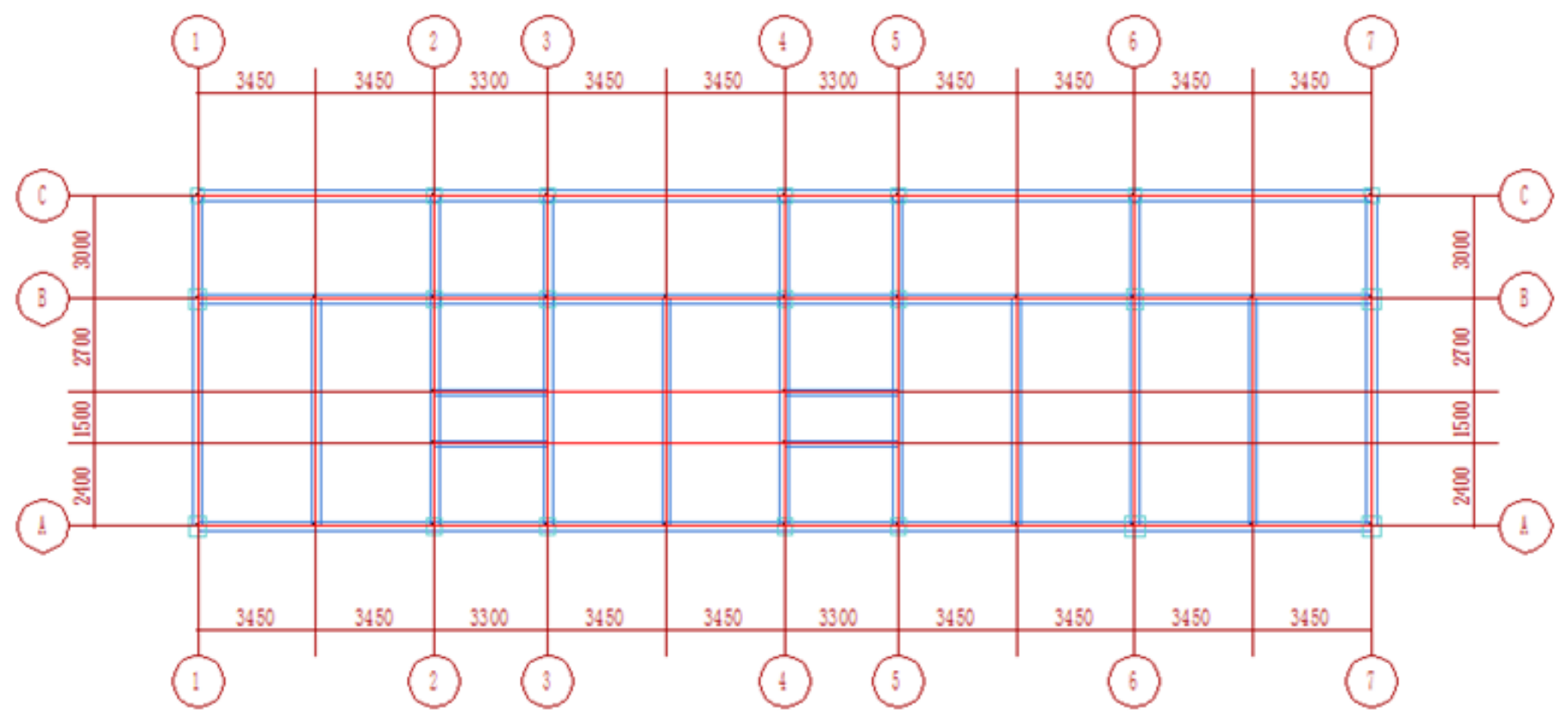

Fig 3: 1st Floor to 4th Floor Plan 


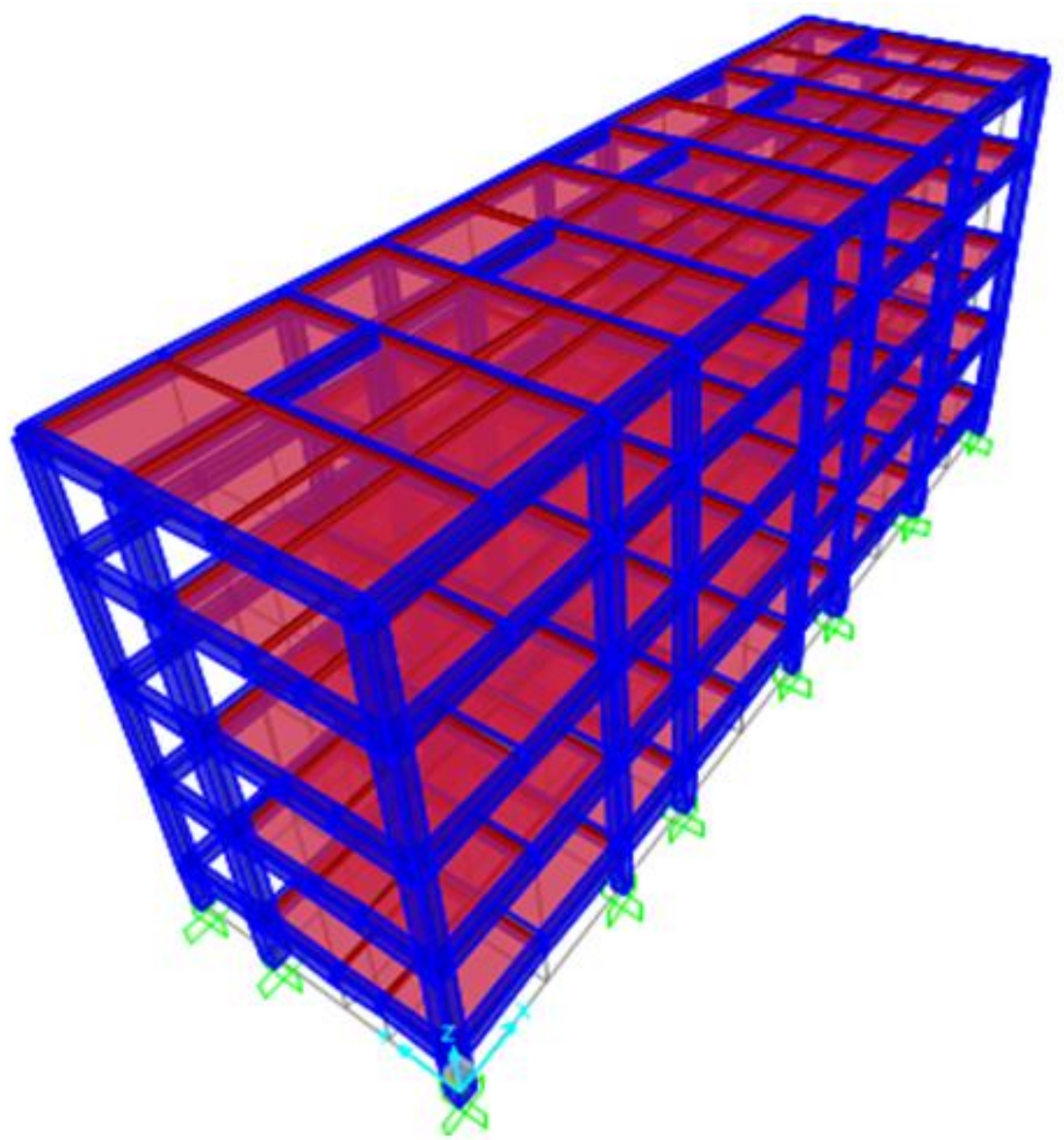

Fig 4: SAP2000 Structural Model

The table 1 below shows the difference between PKPM Nonisolated Periods and SAP2000 with very small value differences indicating a considerable model consistency

Table 1: Non-isolated Periods Compared

\begin{tabular}{|l|l|l|l|}
\hline \multirow{2}{*}{ Mode } & \multicolumn{2}{|l|}{ Non-isolated Periods } & \multirow{2}{*}{ D-value } \\
\cline { 2 - 3 } & PKPM/s & SAP2000/s & \\
\hline 1 & 0.6345 & 0.6345 & 0 \\
\hline 2 & 0.6153 & 0.591 & 0.0243 \\
\hline 3 & 0.5551 & 0.541 & 0.0141 \\
\hline
\end{tabular}

\subsection{Selection of Ground Motion}

According to the seismic building design code GB 500112010, the time history analysis method according to the construction site and design, earthquake ground motion records and artificial acceleration packet selection, including the number of actual earthquake records should not be less than $2 / 3$ of the total earthquake influence coefficient. The average curve of seismic effect coefficient curve of multi time should be adopted by spectrum analysis when the modal decomposition response is consistent in the statistical sense. The elastic time history analysis, structure calculation process of each of the base shear force should not be less than the modal response spectrum calculation results of $65 \%$, also the average value of all time history analysis should not be less than the modal response calculation results of $80 \%$ [7]. 


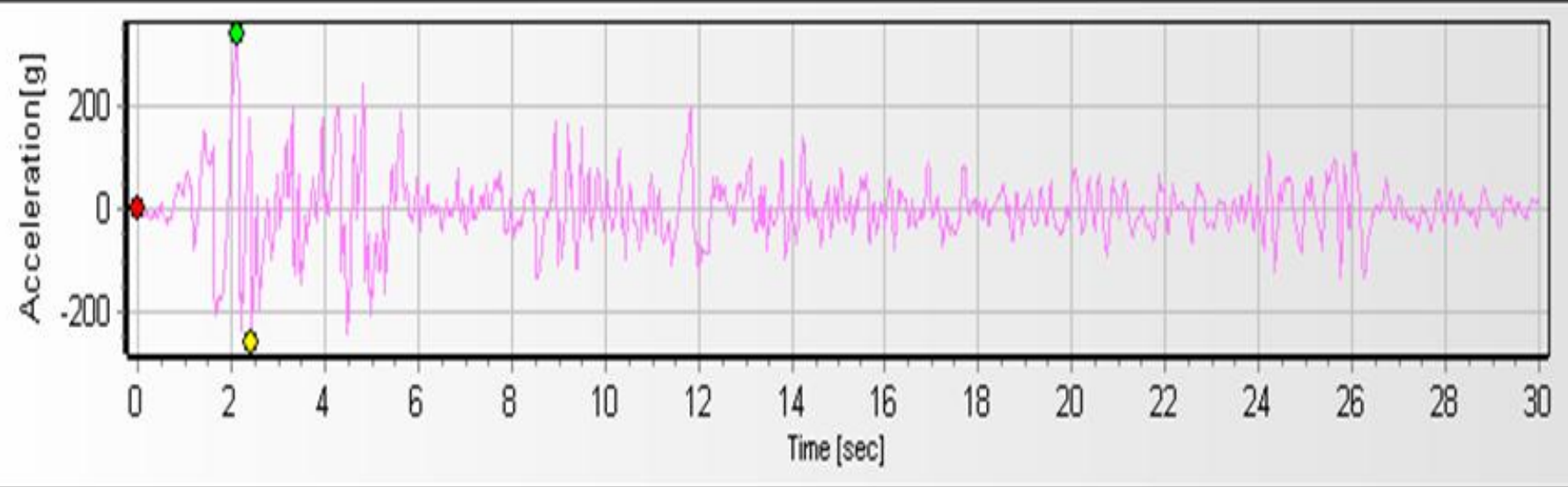

Fig 5: Elcentro Ground Motion

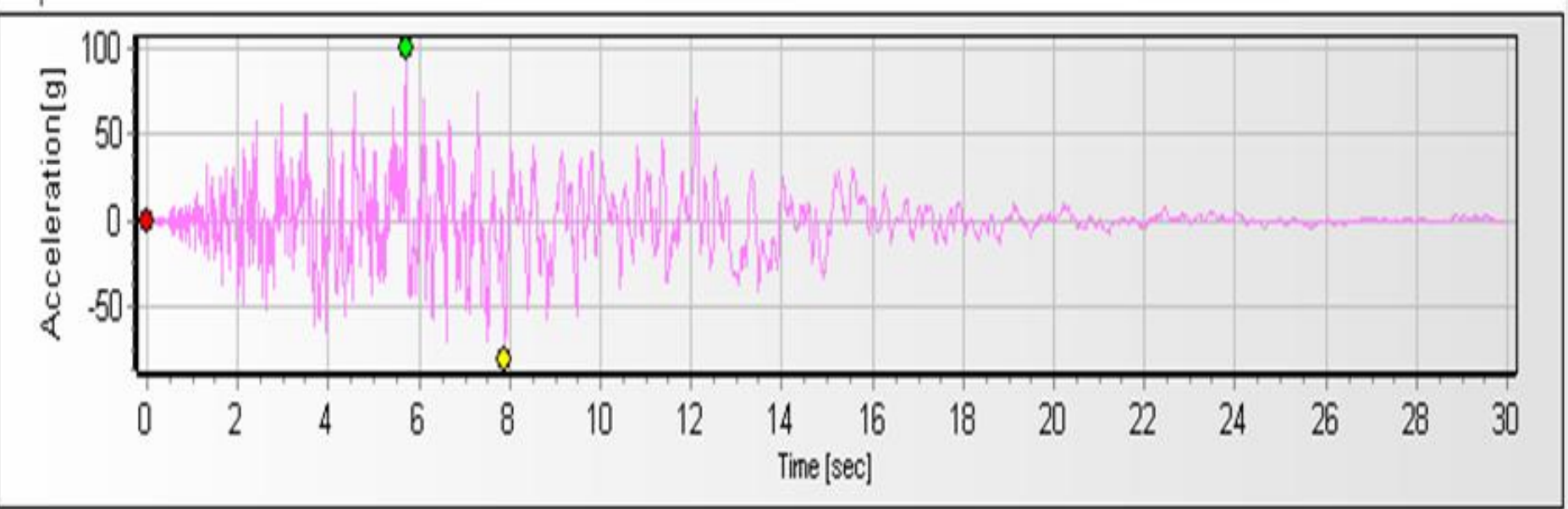

Fig 6: AWR Ground Motion

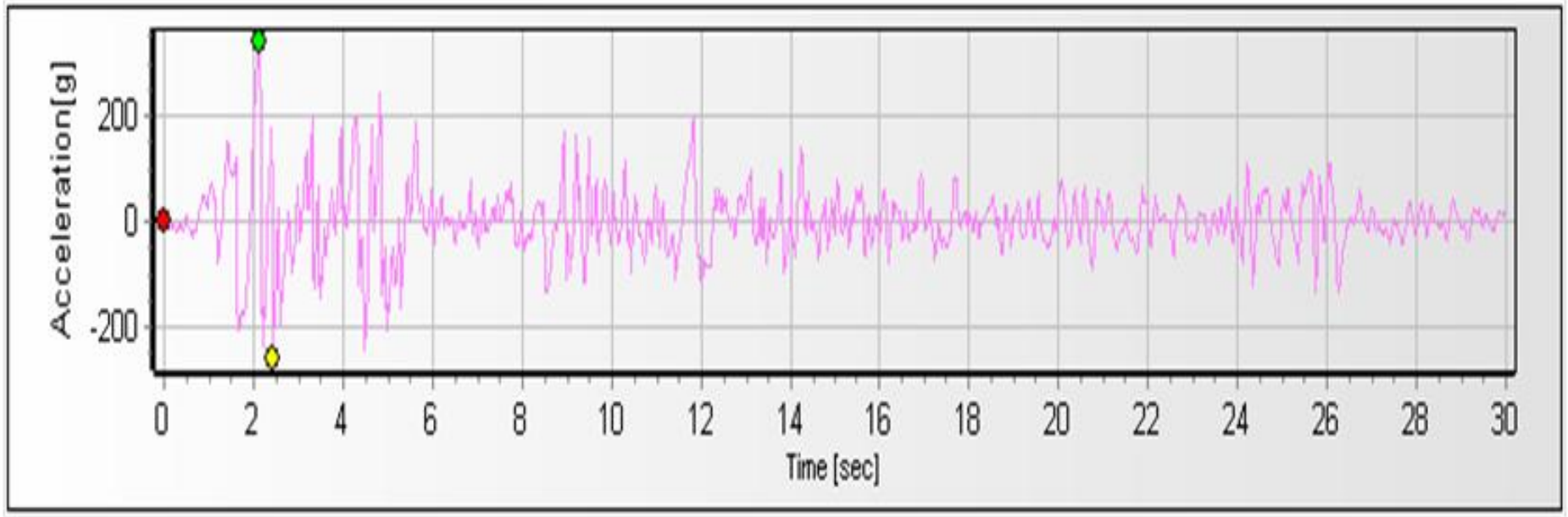

Fig 7: BC Ground Motion

The response spectrum for Zhuoni County is thus constructed with the stipulated provisions from the building seismic parameters with the maximum peak ground acceleration being $0.16 \mathrm{~g}$ for a level 8 at $0.2 \mathrm{~g}$ earthquake site. 


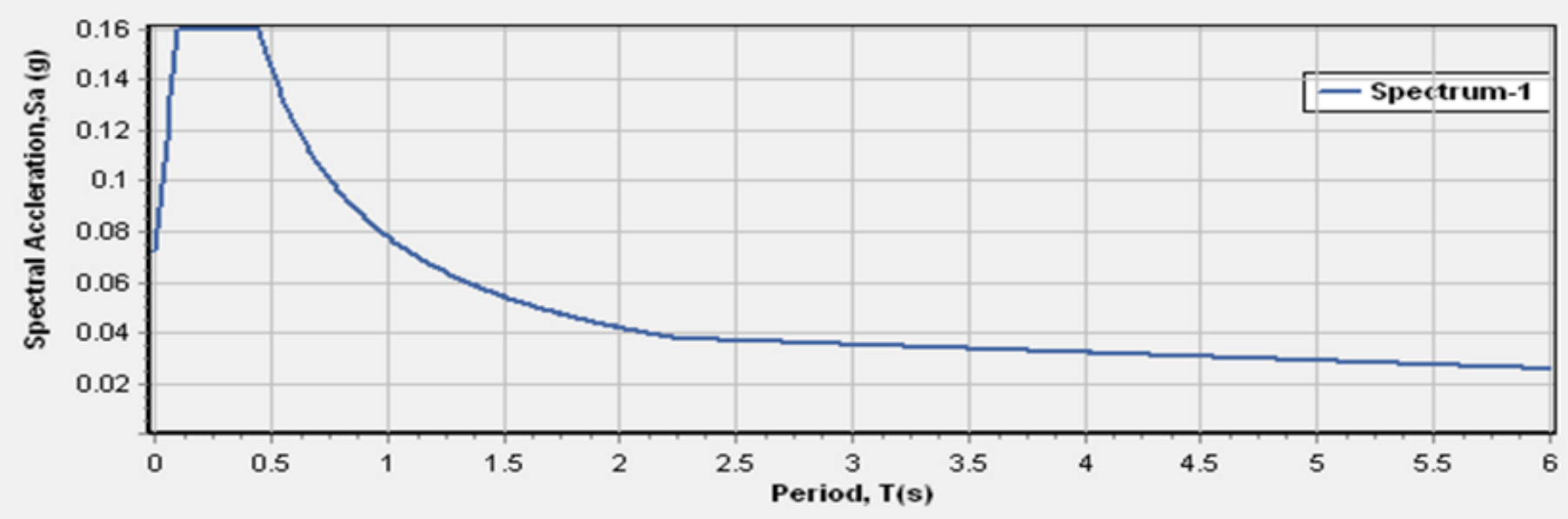

Fig 8: Zhuoni County Response Spectrum

\subsection{Selection and Arrangement of Isolation Device}

In order to achieve the purpose of isolation, it is necessary to set up isolation device at the support to extend the natural vibration period of the structure and reduce the earthquake effect. According to the axial force of the bottom support of the structure under self weight and load, the isolation bearing is selected, and the isolation layer is set on the top surface of the foundation, before the isolation support is arranged.

In this paper all base isolation of model are 10 of LRB400, 6 of LRB500 and 5 of LNR400. The isolator properties and arrangement plan are as shown in table: 2 and the Fig: 9 respectively.

Table 2: Selected Isolators and Their Properties

\begin{tabular}{|c|c|c|c|c|c|c|c|}
\hline \multirow[b]{2}{*}{$\begin{array}{l}\text { Model } \\
\text { Number }\end{array}$} & \multirow[b]{2}{*}{$\begin{array}{l}\text { Effective } \\
\text { Diameter }\end{array}$} & \multirow[b]{2}{*}{$\begin{array}{l}\text { Rubber } \\
\text { Total } \\
\text { Thickness }\end{array}$} & \multirow[b]{2}{*}{$\begin{array}{l}\text { Pre Yield } \\
\text { Stiffness }\end{array}$} & \multicolumn{2}{|l|}{ Equivalent Stiffness } & \multirow[b]{2}{*}{$\begin{array}{l}\text { Vertical } \\
\text { Stiffness }\end{array}$} & \multirow[b]{2}{*}{$\begin{array}{l}\text { yield } \\
\text { strength }\end{array}$} \\
\hline & & & & $\begin{array}{l}\text { Horizontal } \\
\text { Deformation, } 100 \%\end{array}$ & $\begin{array}{l}\text { Horizontal } \\
\text { Deformation, } 250 \%\end{array}$ & & \\
\hline & (mm) & $(\mathrm{mm})$ & $\mathrm{KN} / \mathrm{m}$ & $\mathrm{KN} / \mathrm{m}$ & $\mathrm{KN} / \mathrm{m}$ & $\mathrm{KN} / \mathrm{mm}$ & KN \\
\hline LRB500 & 500 & 92 & 10910 & 1270 & 1010 & 2400 & 40 \\
\hline LRB400 & 400 & 73 & 8790 & 1040 & 820 & 2200 & 20 \\
\hline NRB400 & 400 & 73 & - & 660 & & 1600 & - \\
\hline
\end{tabular}

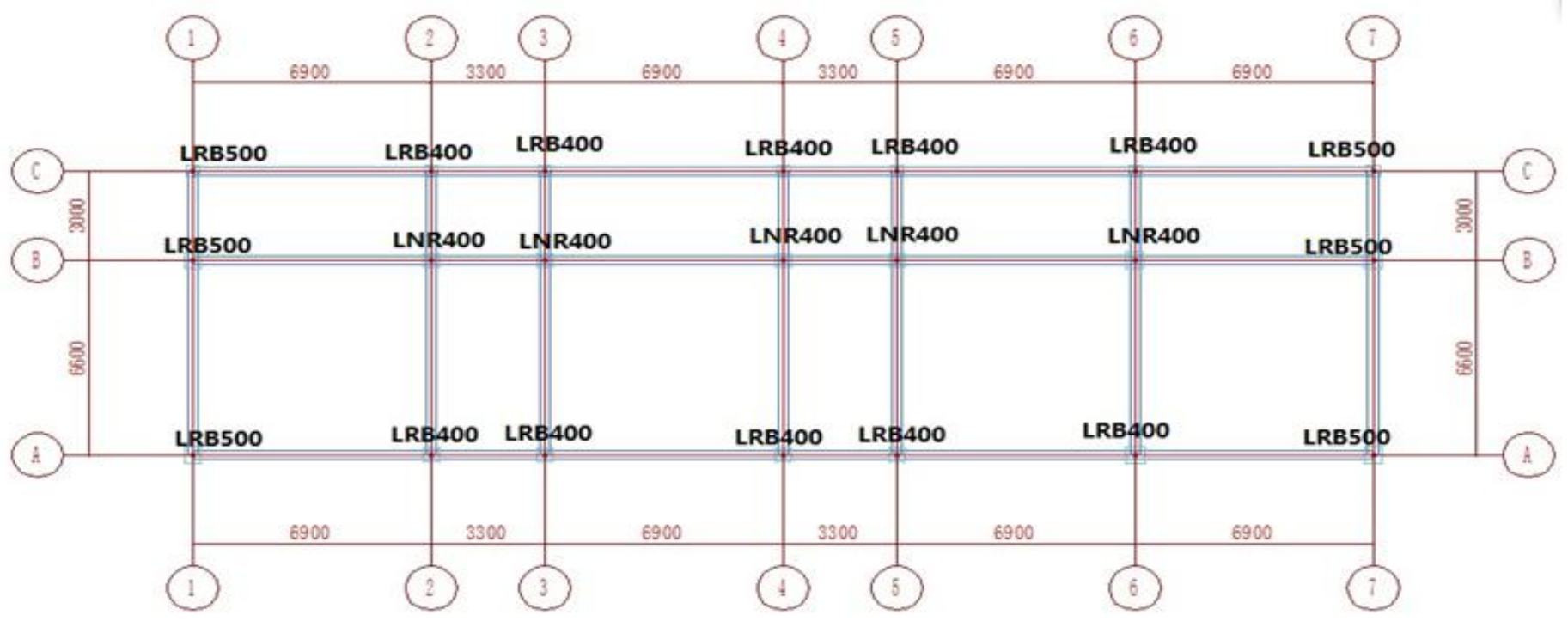

Fig 9: Isolation Device Arrangment Plan 


\section{RESULTS AND DISCUSION}

The frame structural concrete of middle school building is analyzed by time history using three ground motions [Elcentro, AWR (ArtWav-RH2TG040, Tg 0.40) and BC (BajiaCalifonia_No_585, Tg 0.21)] and comparison with response spectrum analysis as well. The non isolated maximum floor accelerations is as shown in Fig 10, maximum velocities as shown in Fig 11, maximum displacements as shown in Fig: 12 and maximum shear forces as shown in Fig: 13 respectively.

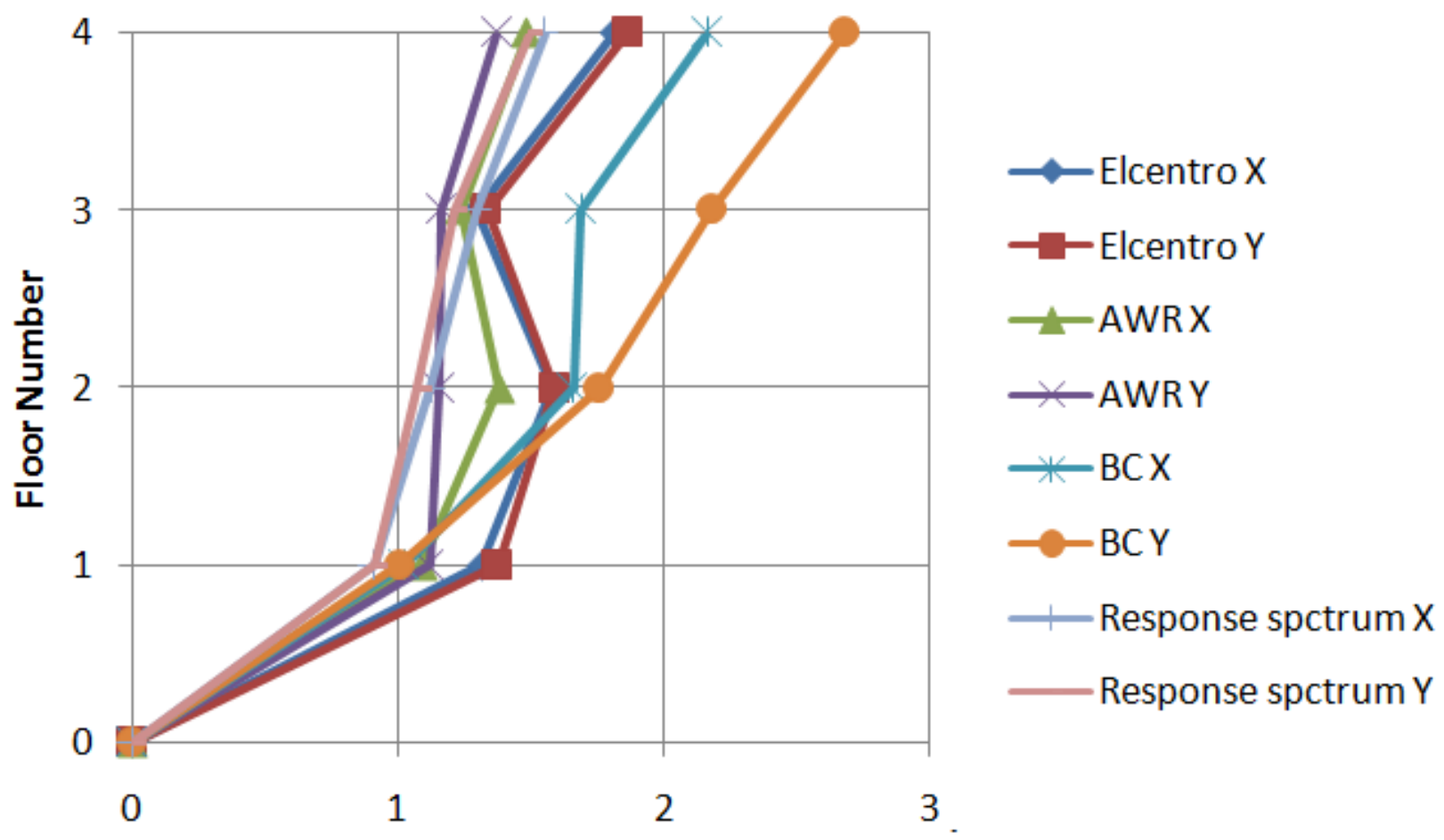

Fig 10: Non-isolated Maximum Floor Accelerations

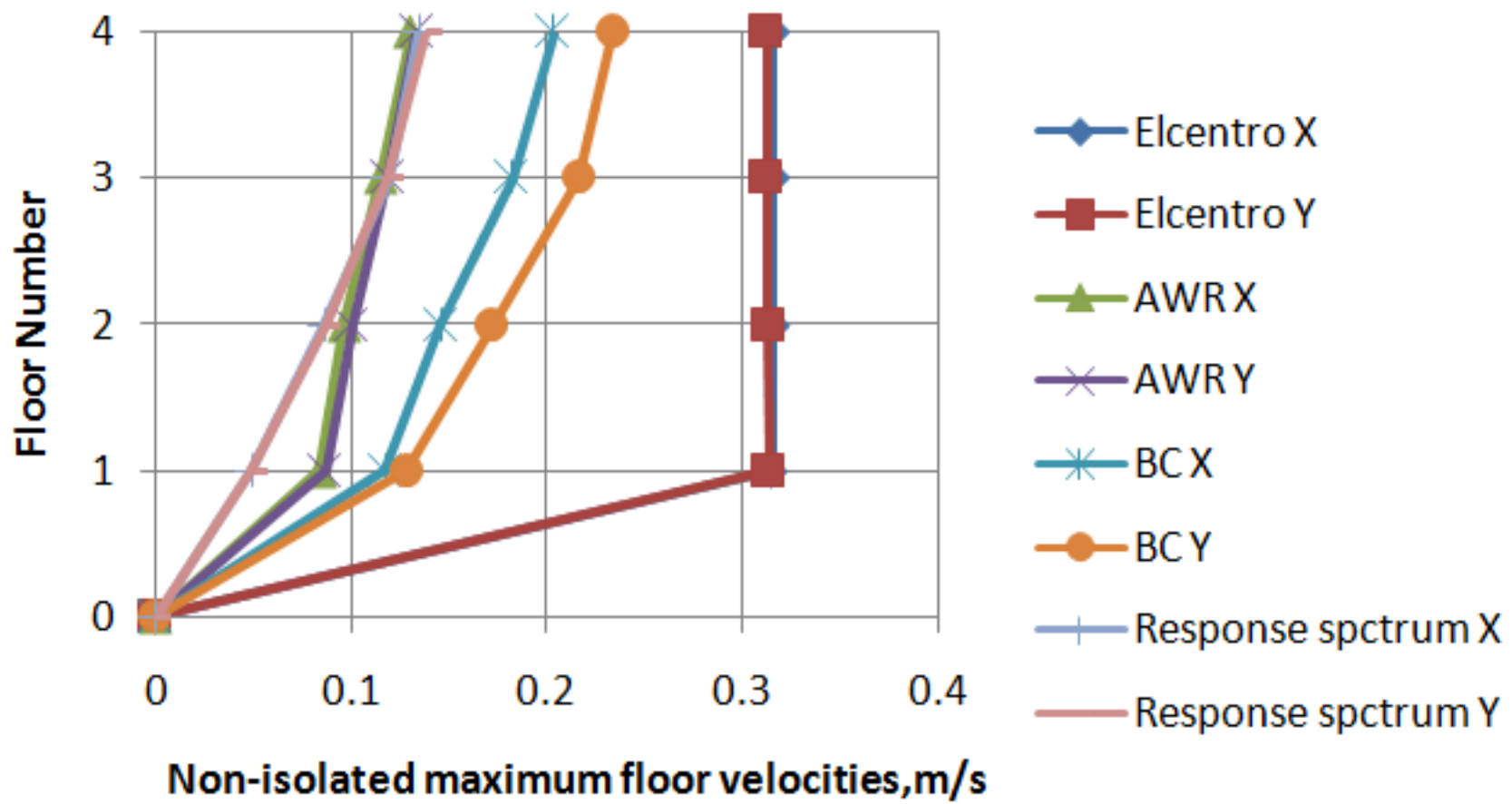

Fig 11: Non-isolated Maximum Floor Velocities 


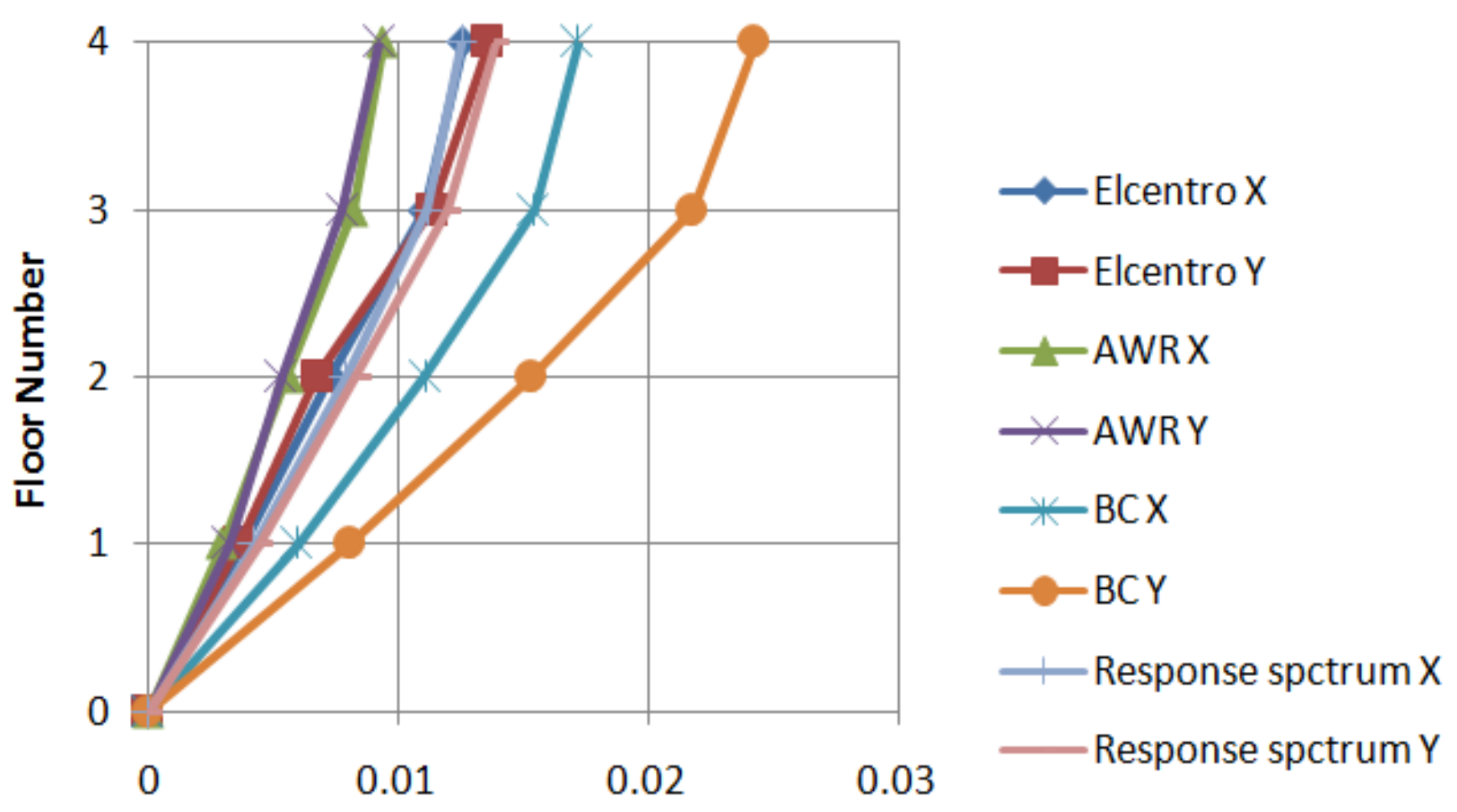

Non-isolated maximum floor displacements, $\mathrm{m}$

Fig 12: Non-isolated Maximum Floor Displacements

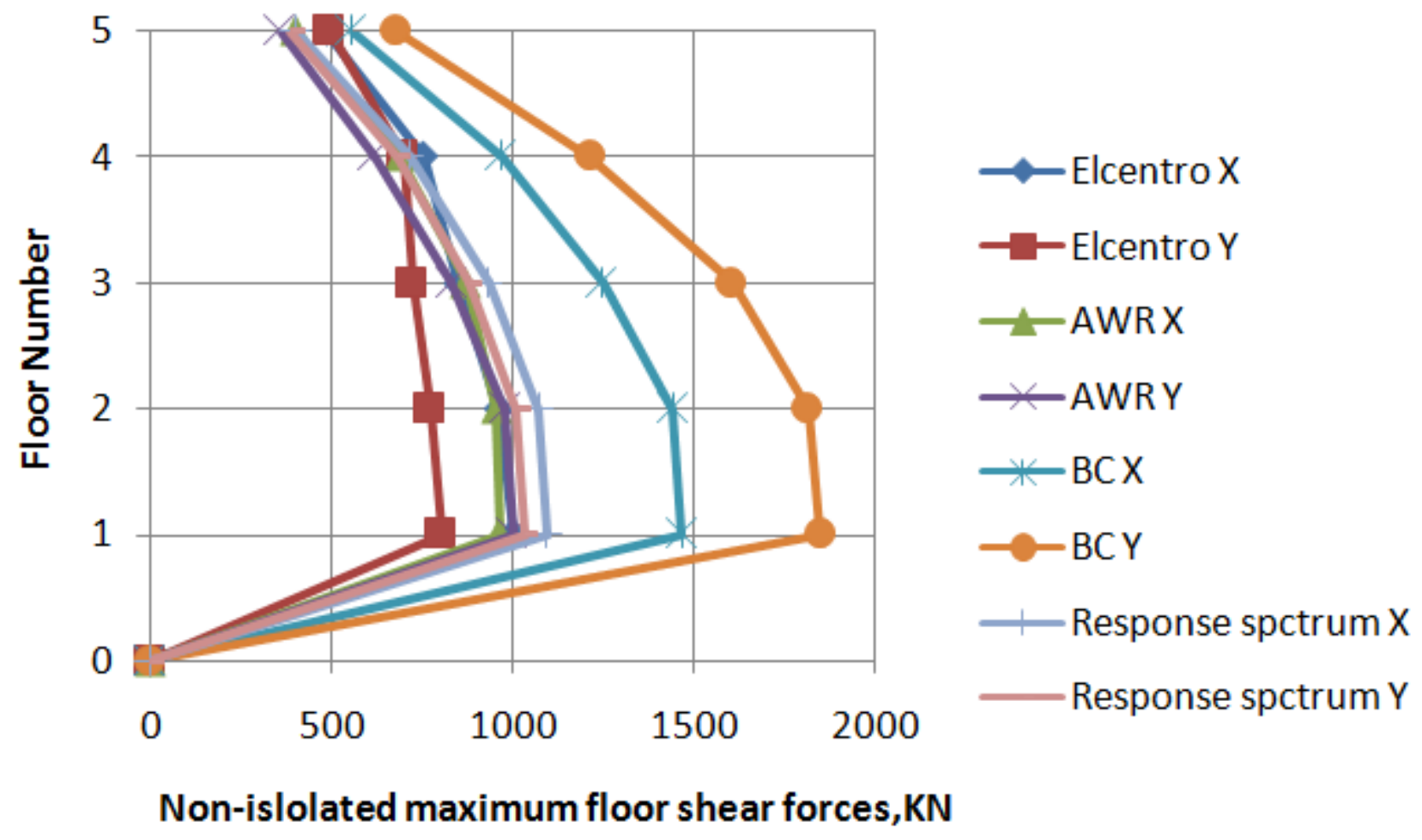

Fig 13: Non-isolated Maximum Floor Shear Forces 
According to the Chinese seismic building design code GB50011-2010, each all time history of the ratio of base shear forces should be more than the response spectrum method result of $65 \%$. The calculated result of time history average shear force is greater than the response spectrum method results of $114 \%$.

Table 3: Base Shear Forces Time History-Response Spectrum Ratios

\begin{tabular}{|l|l|l|l|l|}
\hline \multirow{2}{*}{ Wave type } & \multicolumn{3}{|l|}{ X } & Y \\
\cline { 2 - 5 } & Base forces & Time history /RS & Base forces & TH/RS \\
\hline RS & 1094.464 & - & 1031.217 & - \\
\hline Elcentro & 1001.567 & $91.51 \%$ & 801.396 & $77.71 \%$ \\
\hline AWR & 963.247 & $88.01 \%$ & 980.203 & $95.05 \%$ \\
\hline BC & 1467.034 & $134.04 \%$ & 1848.425 & $179.25 \%$ \\
\hline Average & 1143.95 & $104.52 \%$ & 1210.008 & $117.34 \%$ \\
\hline
\end{tabular}

In the isolated model as shown in Fig 14, the model structure used Sap2000 software in its analysis. All base isolation of the model are 10 of LRB400, 6 of LRB500 and 5 of LNR400. The model structure of the non-isolation bearing and the structure of the isolation bearing were analyzed, and got a two order model, two and three order vibration cycle as shown in
Table 4. Data from table 4 shows, in the arrangement of bearings, the structure vibration cycle was prolonged by successfully avoiding the predominant period, to avoid the occurrence of resonance, so as to effectively reduce the structural seismic response.

Table 4: Non-isolated Periods and Isolated Periods

\begin{tabular}{|l|l|l|}
\hline Mode & Non-isolated Periods & $\begin{array}{l}\text { Isolated } \\
\text { Periods }\end{array}$ \\
\hline 1 & 0.6345 & 1.7925 \\
\hline 2 & 0.591 & 1.7287 \\
\hline 3 & 0.591 & 1.491 \\
\hline
\end{tabular}

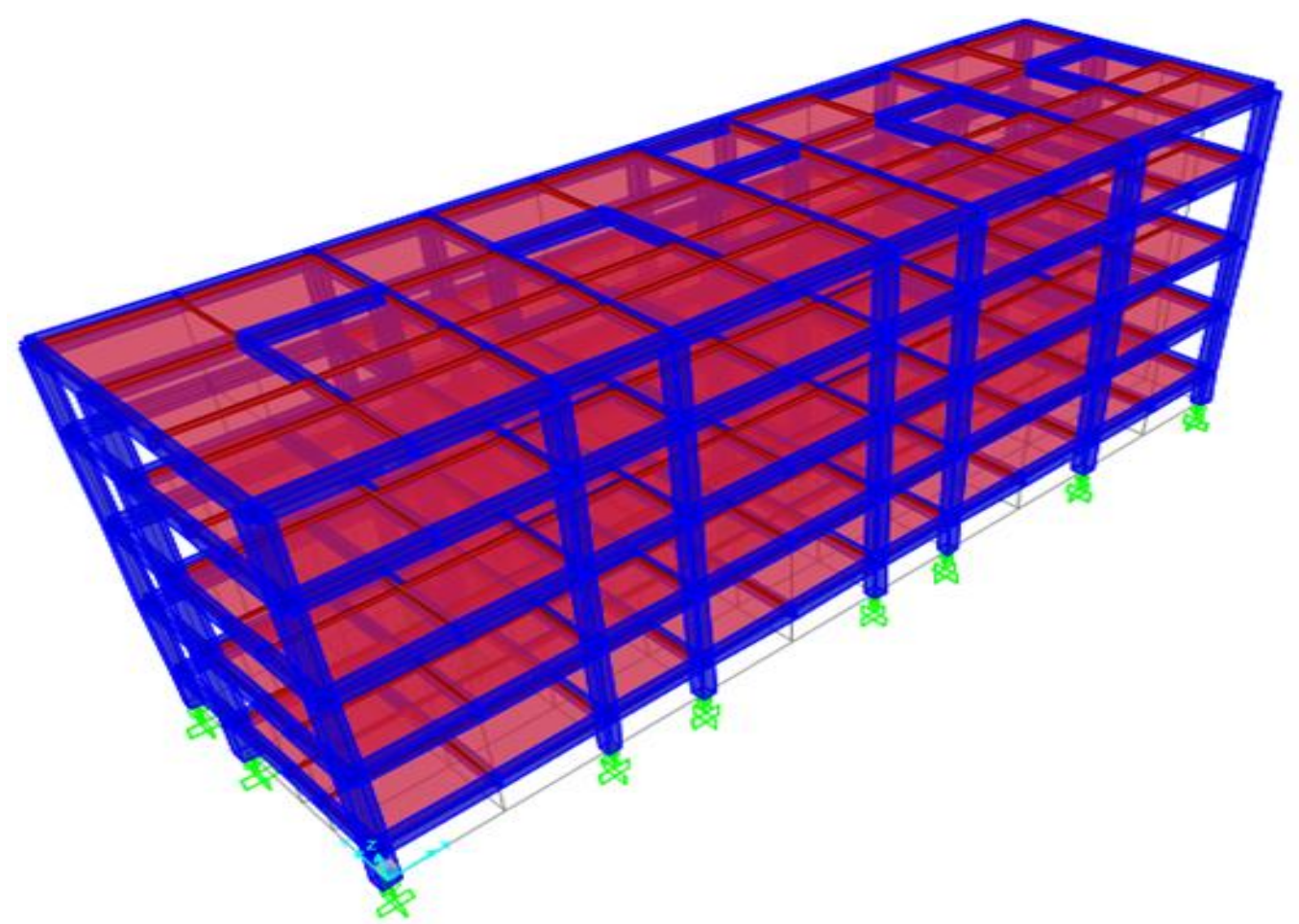

Fig 14: Isolated Building Model 
The frame structure was also isolated with three ground motions. The isolated maximum floor accelerations are shown in Fig 15, maximum velocities as shown in Fig 16, maximum displacements as shown in Fig 17 and maximum shear forces as shown in Fig 18 respectively.

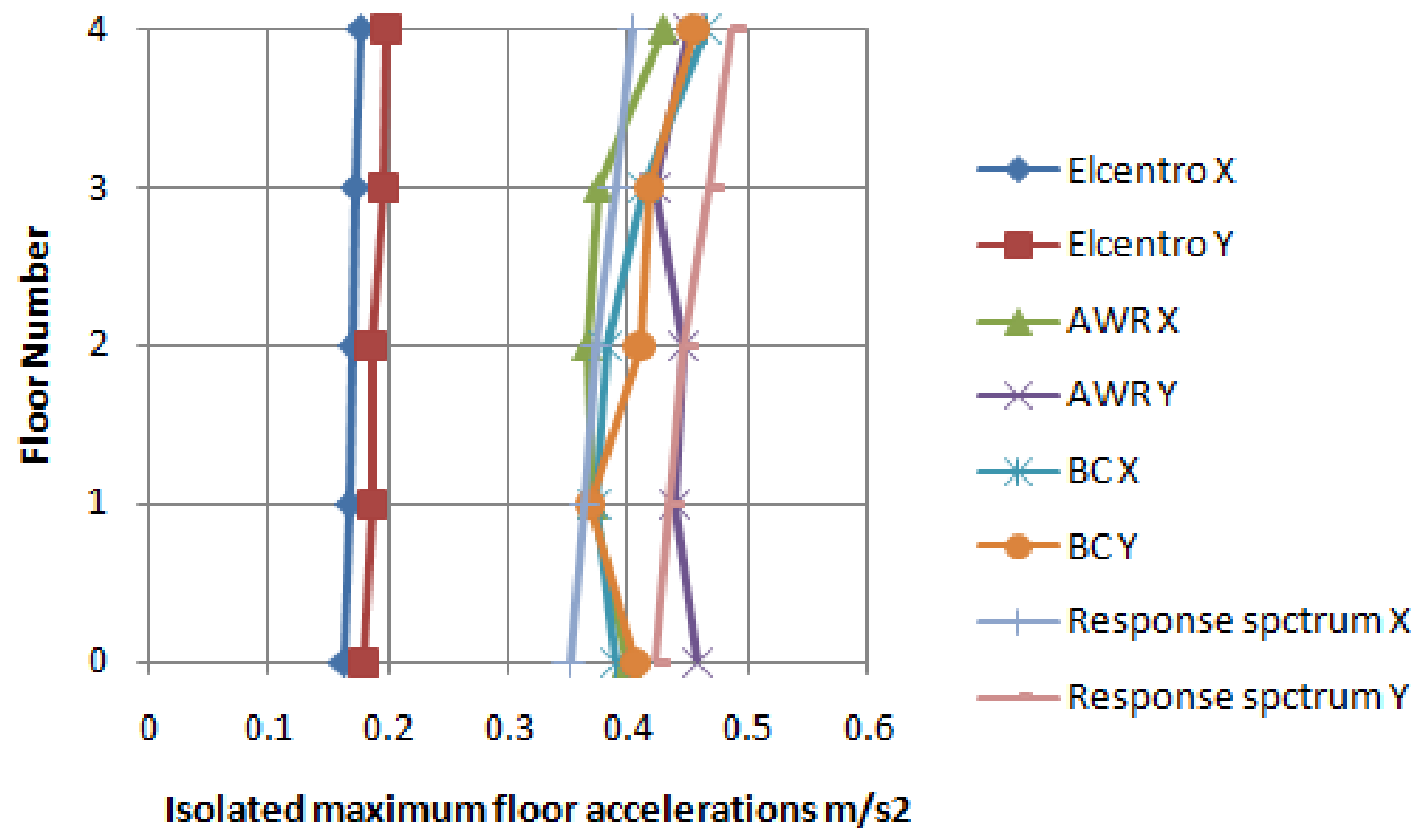

Fig 15: Isolated Maximum Floor Accelerations

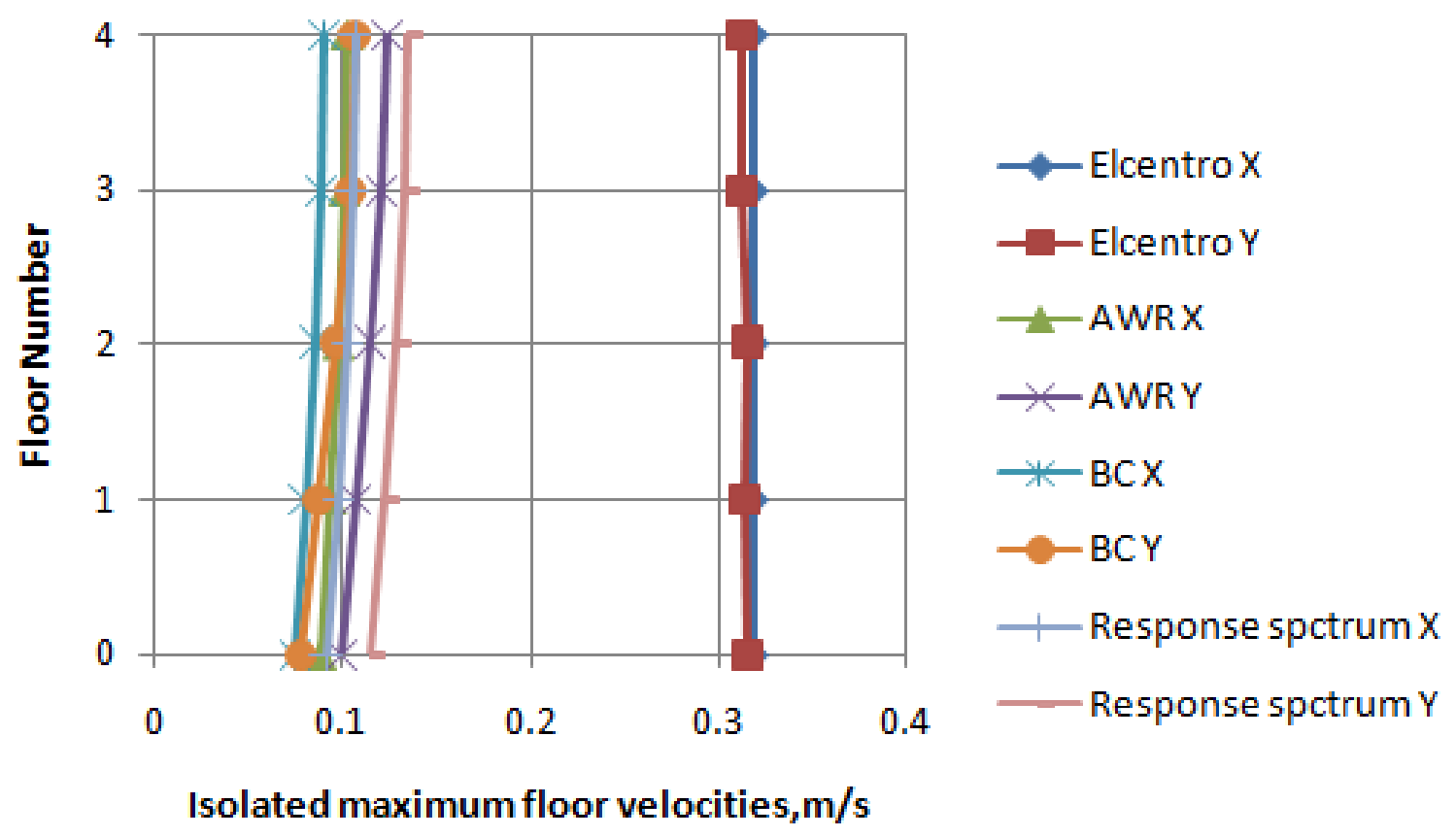

Fig 16: Isolated Maximum Floor Velocities 


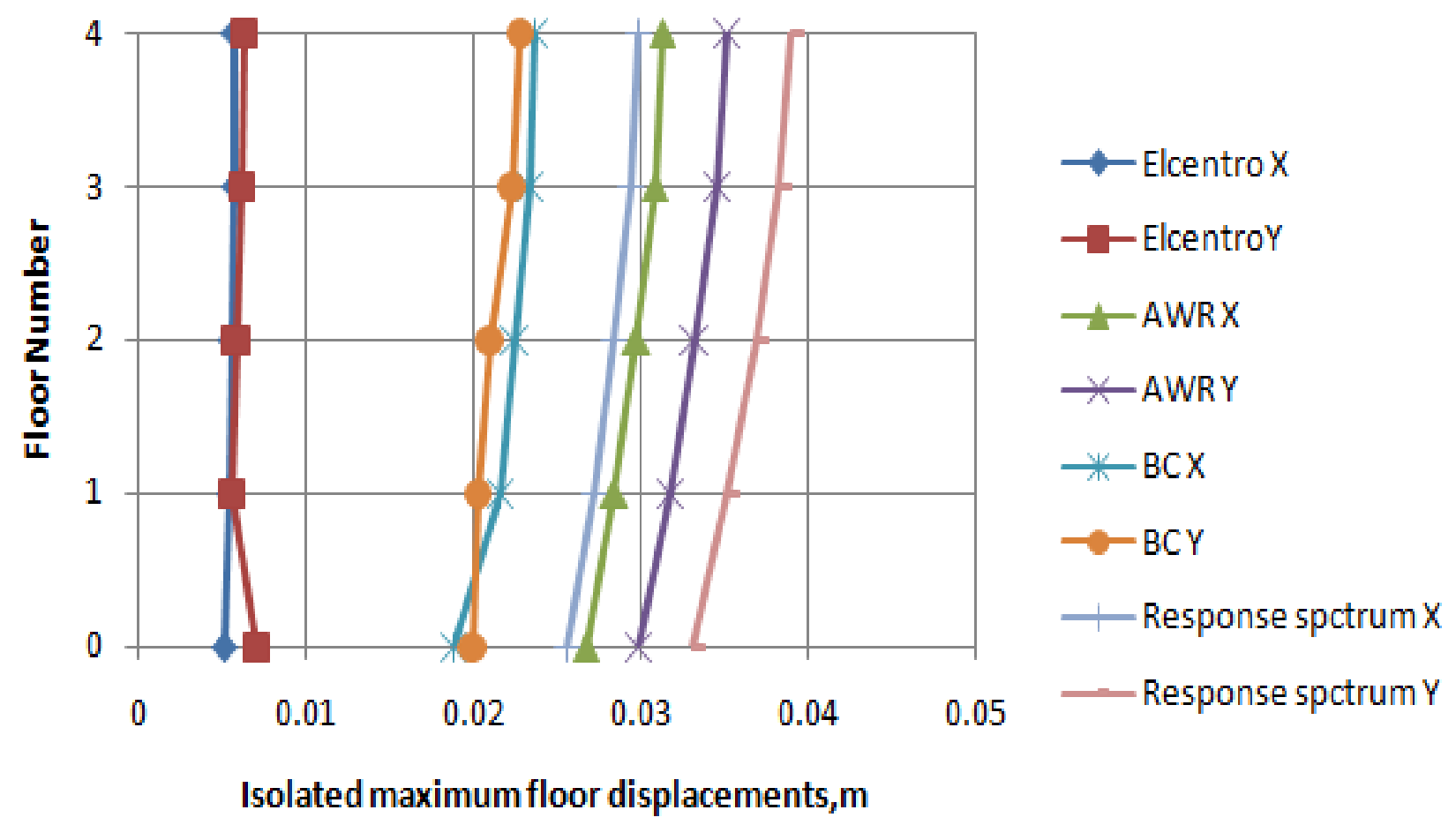

Fig 17: Isolated Maximum Floor Displacements

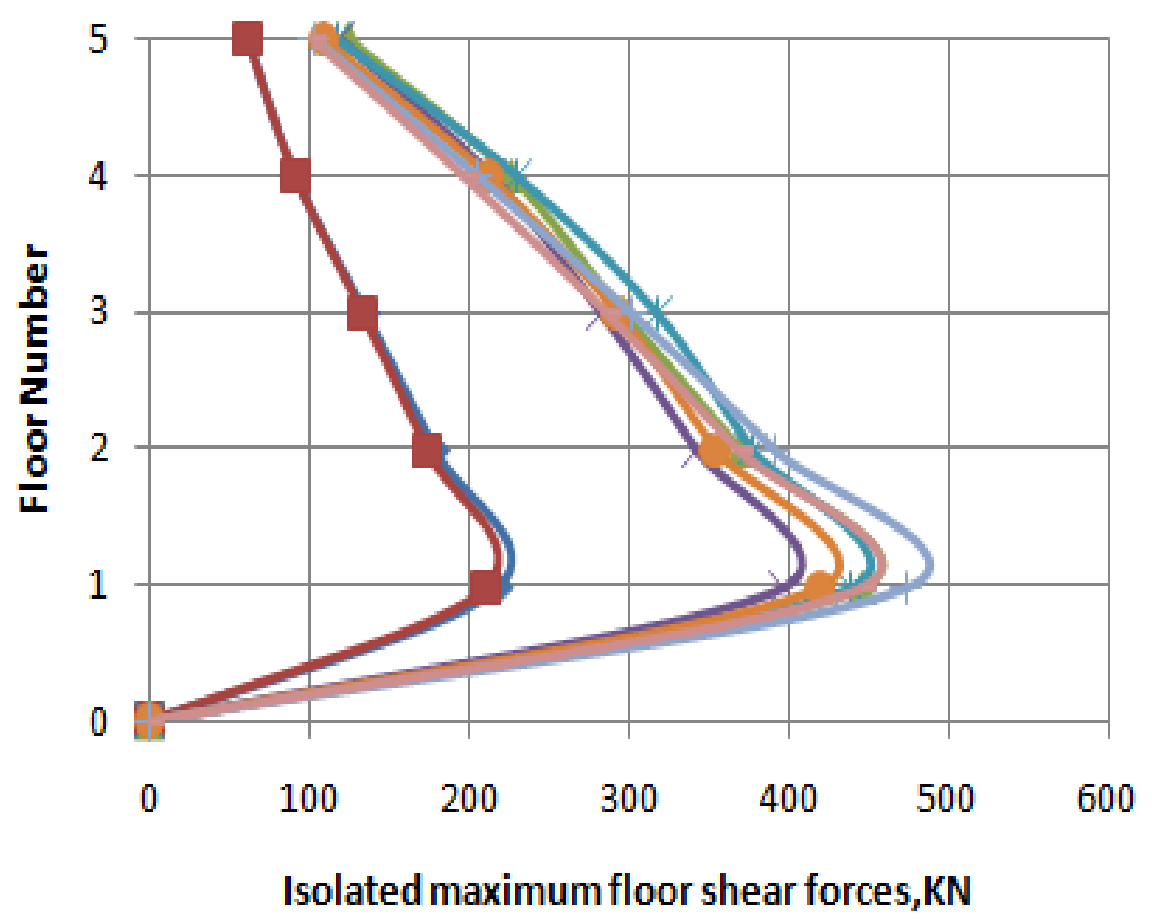

$\longrightarrow$ ElcentroX

- ElcentroY

$\rightarrow$ AWRX

$\because$ AWRY

* $\mathrm{BCX}$

$-\mathrm{BCY}$

—-Response spctrum X

Response spctrum $Y$

Fig 18: Isolated Maximum Floor Shear Forces

Isolated structure shear forces and non isolated structure shear forces ratios are as shows in table: 5 below. 
Table 5: Isolated Structure Shear Forces and Non Isolated Structure Shear Forces Ratios

\begin{tabular}{|l|l|l|l|l|l|l|}
\hline \multirow{2}{*}{ Wave type } & \multicolumn{6}{l}{ Isolated and non isolated shear forces ratios } \\
\cline { 2 - 7 } & Direction & 4th floor & 3rd floor & 2nd floor & 1st floor & base floor \\
\hline \multirow{2}{*}{ Elcentro } & $\mathrm{X}$ & 0.126 & 0.122 & 0.159 & 0.185 & 0.227 \\
\cline { 2 - 7 } & $\mathrm{Y}$ & 0.124 & 0.130 & 0.185 & 0.225 & 0.262 \\
\hline \multirow{2}{*}{ AWR } & $\mathrm{X}$ & 0.316 & 0.328 & 0.341 & 0.389 & 0.463 \\
\cline { 2 - 7 } & $\mathrm{Y}$ & 0.334 & 0.346 & 0.34 & 0.341 & 0.397 \\
\hline \multirow{2}{*}{$\mathrm{BC}$} & $\mathrm{X}$ & 0.212 & 0.237 & 0.255 & 0.262 & 0.299 \\
\cline { 2 - 7 } & $\mathrm{Y}$ & 0.160 & 0.174 & 0.183 & 0.196 & 0.227 \\
\hline \multicolumn{2}{|l|}{ Maximum value } & 0.334 & 0.346 & 0.341 & 0.389 & 0.463 \\
\hline
\end{tabular}

From the table, analysis of the isolated and non isolated structure floor, the maximum shear forces ratios value 0.389 , The maximum influence according to Chinese code 2010, coefficient of seismic horizontal earthquake after isolation is determined by: $\alpha \max 1=\beta \times \alpha \max 1 / \varnothing=0.070$.
Non isolated and isolated accelerations, displacements and shear forces are shown in tables 6,7 and 8 respectively.

Table 6: Comparison of Non-isolated and Isolated Accelerations

\begin{tabular}{|c|c|c|c|c|c|}
\hline \multirow{2}{*}{ Wave type } & \multirow{2}{*}{ Direction } & \multicolumn{4}{|c|}{ Non isolated Accelerations } \\
\hline & & 4th floor & 3rd floor & 2nd floor & 1st floor \\
\hline \multirow{2}{*}{ Elcentro } & $X$ & 1.82 & 1.3 & 1.58 & 1.31 \\
\hline & $\mathrm{Y}$ & 1.86 & 1.3 & 1.59 & 1.38 \\
\hline \multirow{2}{*}{ AWR } & $\mathrm{X}$ & 1.49 & 1.23 & 1.38 & 1.09 \\
\hline & $\mathrm{Y}$ & 1.37 & 1.17 & 1.15 & 1.12 \\
\hline \multirow{2}{*}{$\mathrm{BC}$} & $\mathrm{X}$ & 2.17 & 1.69 & 1.66 & 1.03 \\
\hline & $\mathrm{Y}$ & 2.68 & 2.18 & 1.76 & 1 \\
\hline \multirow{2}{*}{ Average } & $\mathrm{X}$ & 1.83 & 1.41 & 1.54 & 1.14 \\
\hline & $\mathrm{Y}$ & 1.97 & 1.55 & 1.50 & 1.17 \\
\hline \multirow{2}{*}{ Wave type } & \multirow{2}{*}{ Direction } & \multicolumn{4}{|c|}{ Isolated Accelerations } \\
\hline & & 4th floor & 3rd floor & 2nd floor & 1 st floor \\
\hline \multirow{2}{*}{ Elcentro } & $X$ & 0.17 & 0.17 & 0.17 & 0.18 \\
\hline & $\mathrm{Y}$ & 0.19 & 0.19 & 0.19 & 0.2 \\
\hline \multirow{2}{*}{ AWR } & $\mathrm{X}$ & 0.43 & 0.38 & 0.36 & 0.37 \\
\hline & $\mathrm{Y}$ & 0.45 & 0.42 & 0.45 & 0.44 \\
\hline \multirow{2}{*}{$\mathrm{BC}$} & $\mathrm{X}$ & 0.41 & 0.38 & 0.37 & 0.46 \\
\hline & $\mathrm{Y}$ & 0.42 & 0.41 & 0.37 & 0.46 \\
\hline \multirow{2}{*}{ Average } & $X$ & 0.34 & 0.31 & 0.30 & 0.34 \\
\hline & $\mathrm{Y}$ & 0.35 & 0.34 & 0.34 & 0.37 \\
\hline
\end{tabular}

Table 7: Comparison of Non-isolated and Isolated Displacements

\begin{tabular}{|l|l|l|l|l|l|}
\hline \multirow{2}{*}{ Wave type } & \multirow{2}{*}{ Direction } & \multicolumn{4}{|l|}{ Non isolated Displacements } \\
\cline { 3 - 6 } & & 4th floor & 3rd floor & 2nd floor & 1st floor \\
\hline \multirow{2}{*}{ Elcentro } & $\mathrm{X}$ & 0.013 & 0.011 & 0.0073 & 0.004 \\
\cline { 2 - 6 } & $\mathrm{Y}$ & 0.014 & 0.011 & 0.007 & 0.004 \\
\hline AWR & $\mathrm{X}$ & 0.009 & 0.008 & 0.006 & 0.003 \\
\hline
\end{tabular}




\begin{tabular}{|l|l|l|l|l|l|}
\multicolumn{1}{|l|}{} & $\mathrm{Y}$ & 0.009 & 0.008 & 0.005 & 0.003 \\
\hline \multirow{3}{*}{$\mathrm{BC}$} & $\mathrm{X}$ & 0.017 & 0.015 & 0.011 & 0.006 \\
\cline { 2 - 6 } & $\mathrm{Y}$ & 0.024 & 0.022 & 0.015 & 0.008 \\
\hline \multirow{3}{*}{ Average } & $\mathrm{X}$ & 0.013 & 0.011 & 0.008 & 0.004 \\
\cline { 2 - 6 } & $\mathrm{Y}$ & 0.016 & 0.014 & 0.009 & 0.005 \\
\hline \multirow{3}{*}{ Wave type } & \multirow{2}{*}{ Direction } & \multicolumn{4}{|l|}{ Isolated Displacements } \\
\cline { 2 - 6 } & & 4th floor & 3rd floor & 2nd floor & 1 st floor \\
\hline \multirow{2}{*}{ AWR } & $\mathrm{X}$ & 0.006 & 0.008 & 0.006 & 0.005 \\
\cline { 2 - 6 } & $\mathrm{Y}$ & 0.006 & 0.006 & 0.006 & 0.006 \\
\hline \multirow{2}{*}{ BC } & $\mathrm{X}$ & 0.031 & 0.031 & 0.029 & 0.028 \\
\cline { 2 - 6 } & $\mathrm{Y}$ & 0.035 & 0.035 & 0.033 & 0.032 \\
\hline \multirow{2}{*}{ Average } & $\mathrm{X}$ & 0.024 & 0.023 & 0.023 & 0.022 \\
\cline { 2 - 6 } & $\mathrm{X}$ & 0.023 & 0.022 & 0.021 & 0.02 \\
\cline { 2 - 6 } & $\mathrm{Y}$ & 0.020 & 0.021 & 0.019 & 0.018 \\
\hline
\end{tabular}

Table 8: Comparison of Non-isolated and Isolated Shear Forces

\begin{tabular}{|l|l|l|l|l|l|l|}
\hline \multirow{2}{*}{ Wave type } & \multirow{2}{*}{ Direction } & \multicolumn{5}{|l|}{ Non isolated Shear forces } \\
\cline { 3 - 7 } & & 4 th floor & 3rd floor & 2nd floor & 1 st floor & $\begin{array}{l}\text { Base } \\
\text { Floor }\end{array}$ \\
\hline \multirow{2}{*}{ Elcentro } & $\mathrm{X}$ & 484.263 & 753.051 & 850.289 & 961.716 & 1001.567 \\
\cline { 2 - 7 } & $\mathrm{Y}$ & 493.625 & 699.128 & 722.112 & 771.332 & 801.396 \\
\hline \multirow{3}{*}{ AWR } & $\mathrm{X}$ & 397.57 & 689.054 & 870.483 & 952.987 & 963.247 \\
\cline { 2 - 7 } & $\mathrm{Y}$ & 359.007 & 617.438 & 829.938 & 980.203 & 1000.061 \\
\hline \multirow{3}{*}{ BC } & $\mathrm{X}$ & 554.803 & 968.479 & 1247.168 & 1441.683 & 1467.034 \\
\cline { 2 - 7 } & $\mathrm{Y}$ & 678.872 & 1213.738 & 1604.524 & 1816.077 & 1848.425 \\
\hline Average & $\mathrm{X}$ & 478.879 & 803.528 & 989.313 & 1118.795 & 1143.949 \\
\cline { 2 - 7 } & $\mathrm{Y}$ & 510.501 & 843.435 & 1052.191 & 1189.204 & 1216.627 \\
\hline \multirow{2}{*}{ Wave type } & \multirow{2}{*}{ Direction } & Isolated Shear forces & & & \\
\cline { 3 - 7 } & 4 th floor & 3 rd floor & 2 nd floor & 1 st floor & base floor \\
\hline \multirow{2}{*}{ Elcentro } & $\mathrm{X}$ & 60.986 & 91.685 & 135.056 & 178.339 & 218.314 \\
\cline { 2 - 7 } & $\mathrm{Y}$ & 61.172 & 91.132 & 133.566 & 173.914 & 209.908 \\
\hline \multirow{2}{*}{ AWR } & $\mathrm{X}$ & 125.437 & 225.802 & 296.581 & 370.558 & 445.733 \\
\cline { 2 - 7 } & $\mathrm{Y}$ & 120.01 & 213.784 & 282.901 & 341.985 & 396.836 \\
\hline \multirow{2}{*}{ BC } & $\mathrm{X}$ & 117.475 & 229.666 & 317.413 & 378.187 & 439.217 \\
\cline { 2 - 7 } & $\mathrm{Y}$ & 108.731 & 211.734 & 293.824 & 355.687 & 419.854 \\
\hline Average & $\mathrm{X}$ & 101.299 & 182.384 & 249.683 & 309.028 & 367.755 \\
\cline { 2 - 7 } & $\mathrm{Y}$ & 96.638 & 172.217 & 236.764 & 290.529 & 342.199 \\
\hline
\end{tabular}

The isolated structure have increased in displacement and reduced in acceleration and shear forces shown in the graphs Fig19, 20 and Fig 21 respectively 


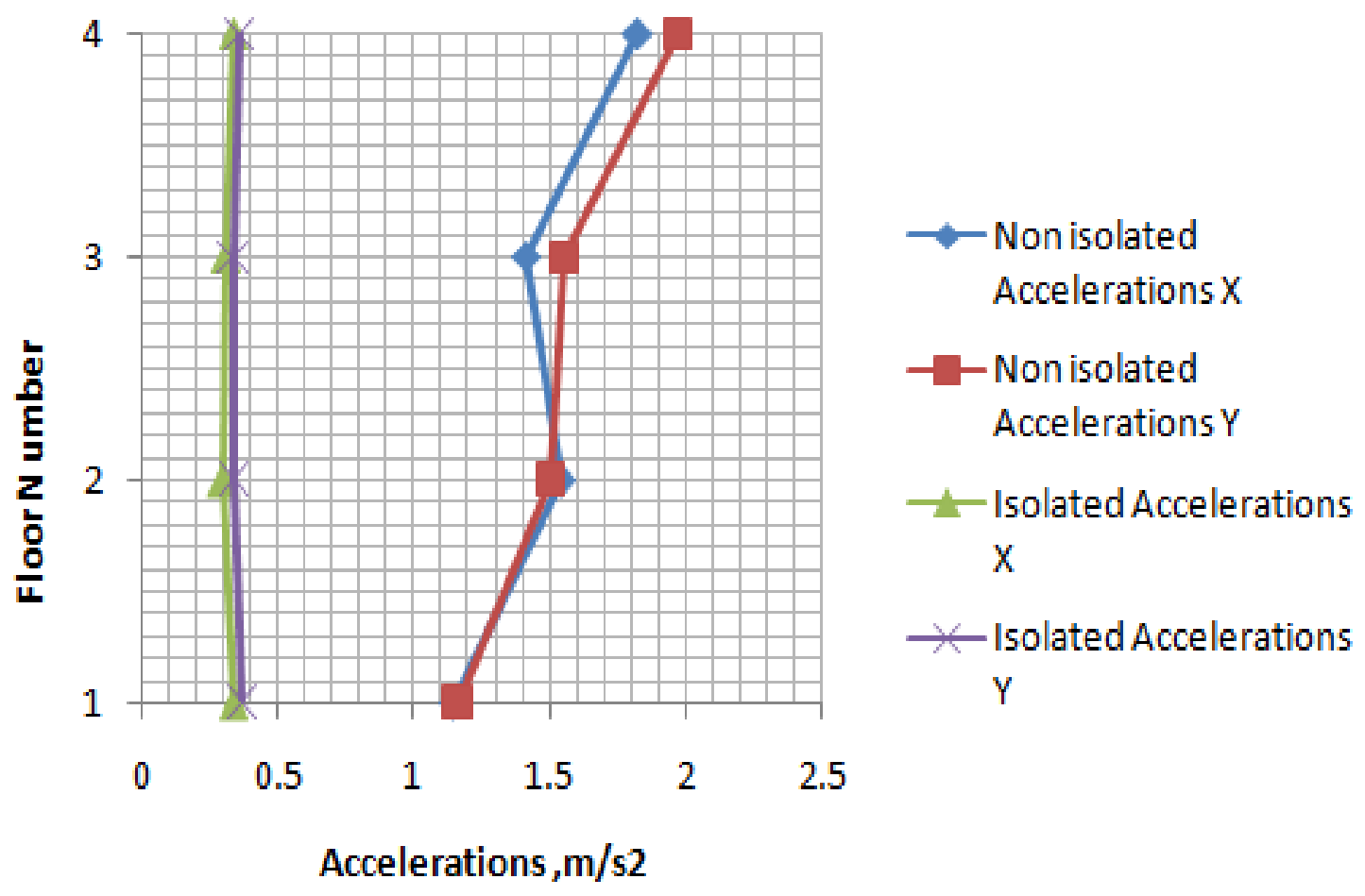

Fig 19: Comparison of Non-isolated and Isolated Accelerations

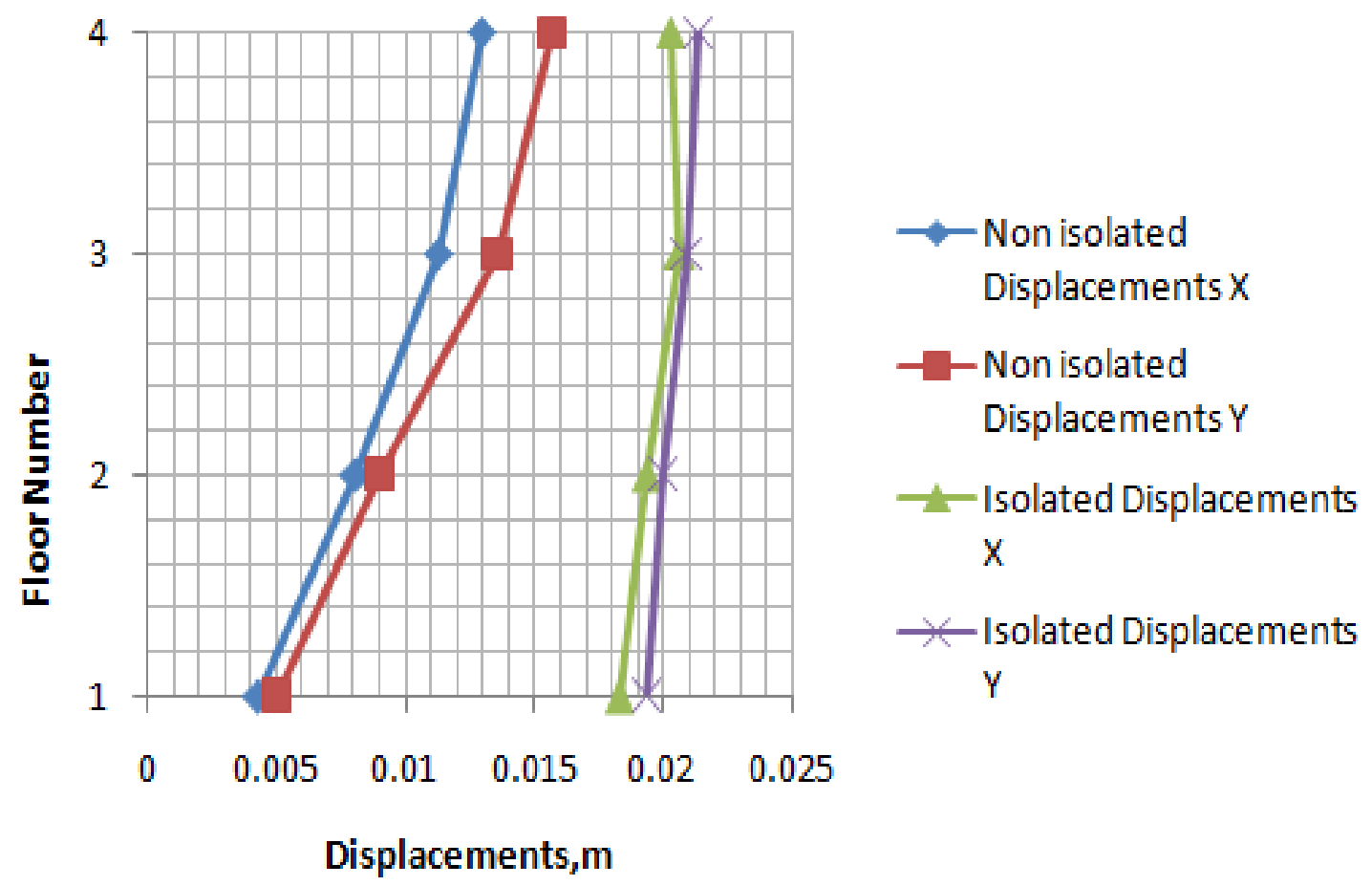

Fig 20: Comparison of Non-isolated and Isolated Displacements 


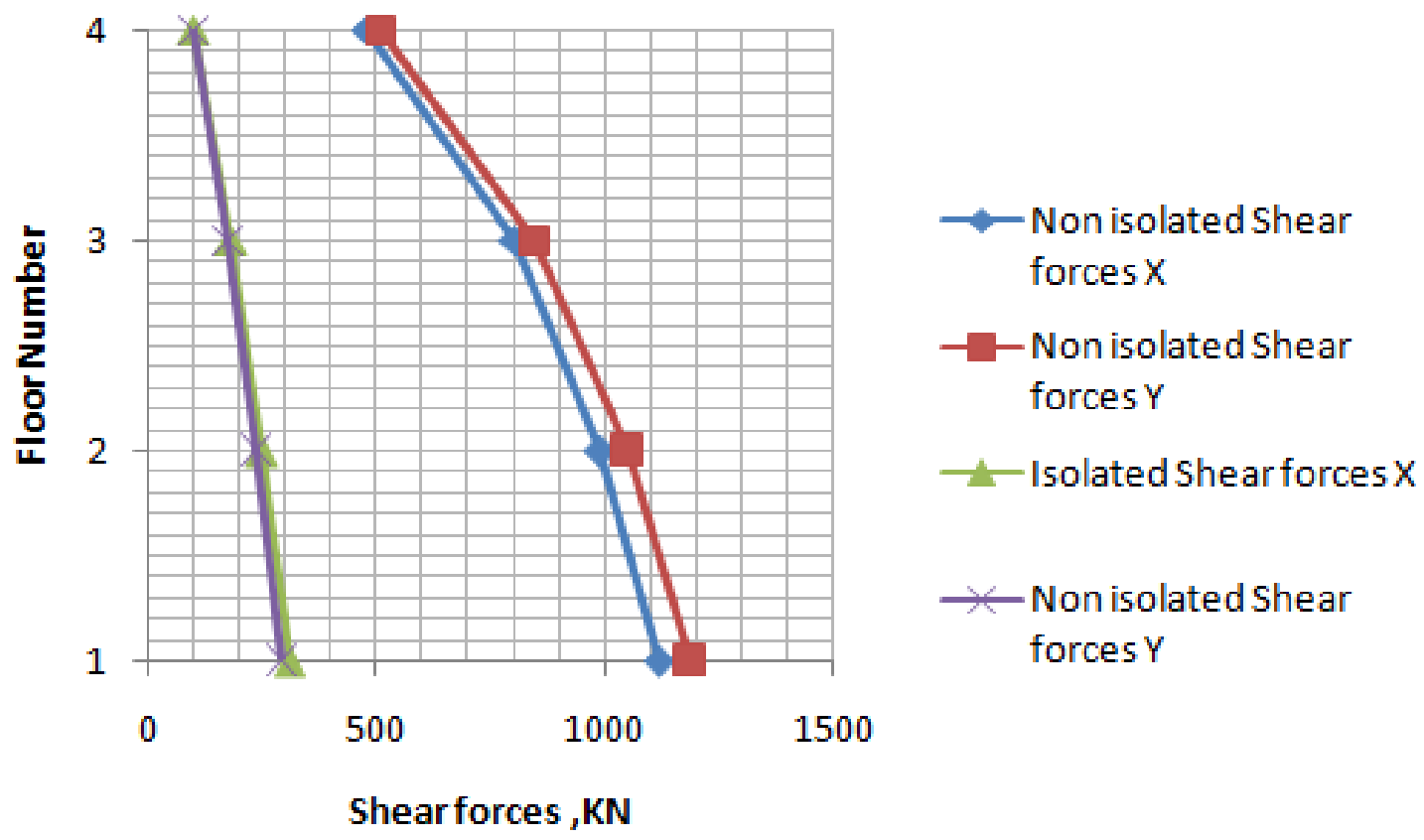

Fig 21: Comparison of Non isolated and Isolated Shear Forces

Graphs of isolated structure and non isolated Base shear forces structure are shown in Fig 22, 23 and Fig 24 respectively. It can be seen intuitively that the isolation bearing is effective.

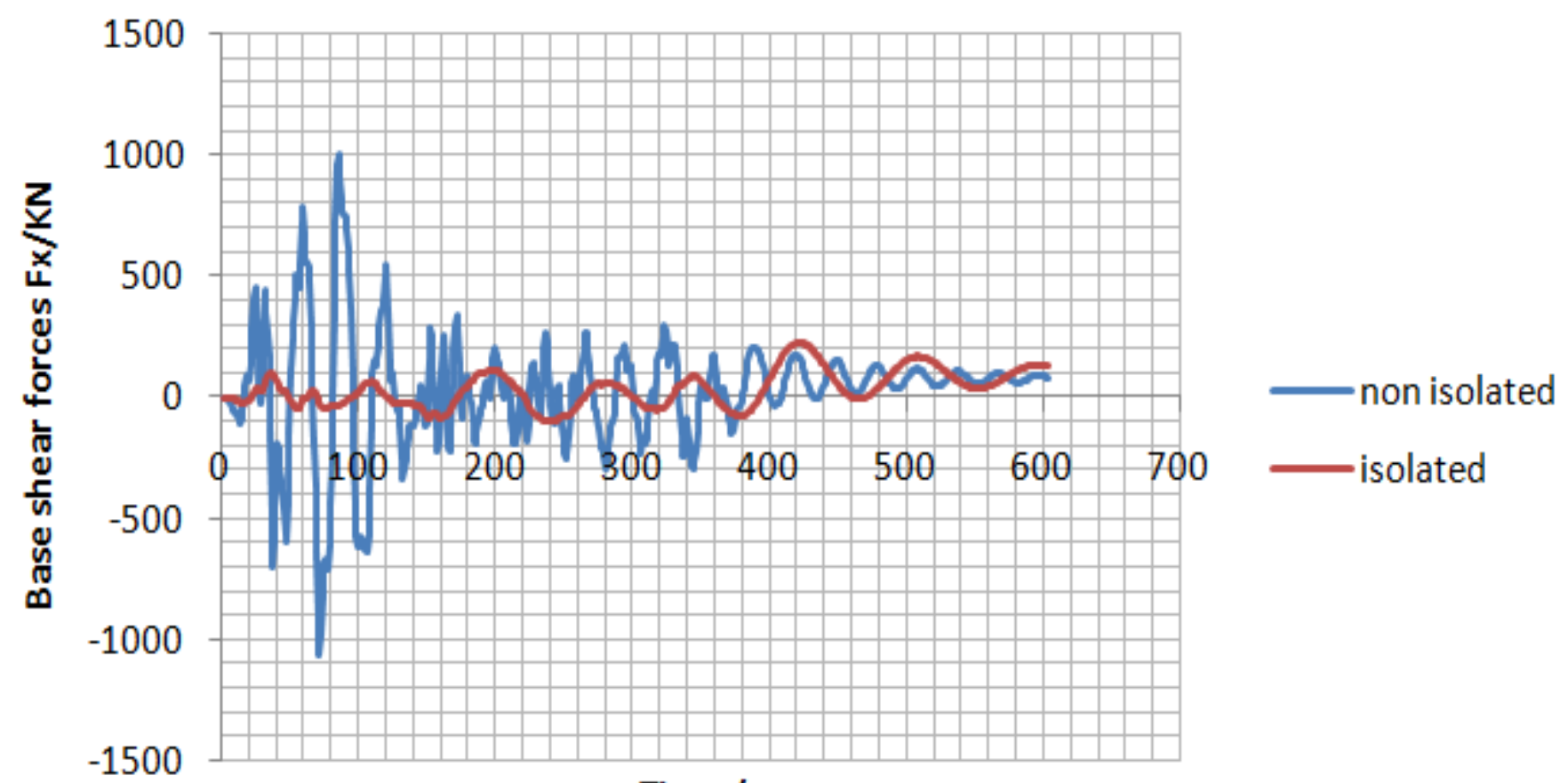

Time /s

Fig 22: El Centro Wave 


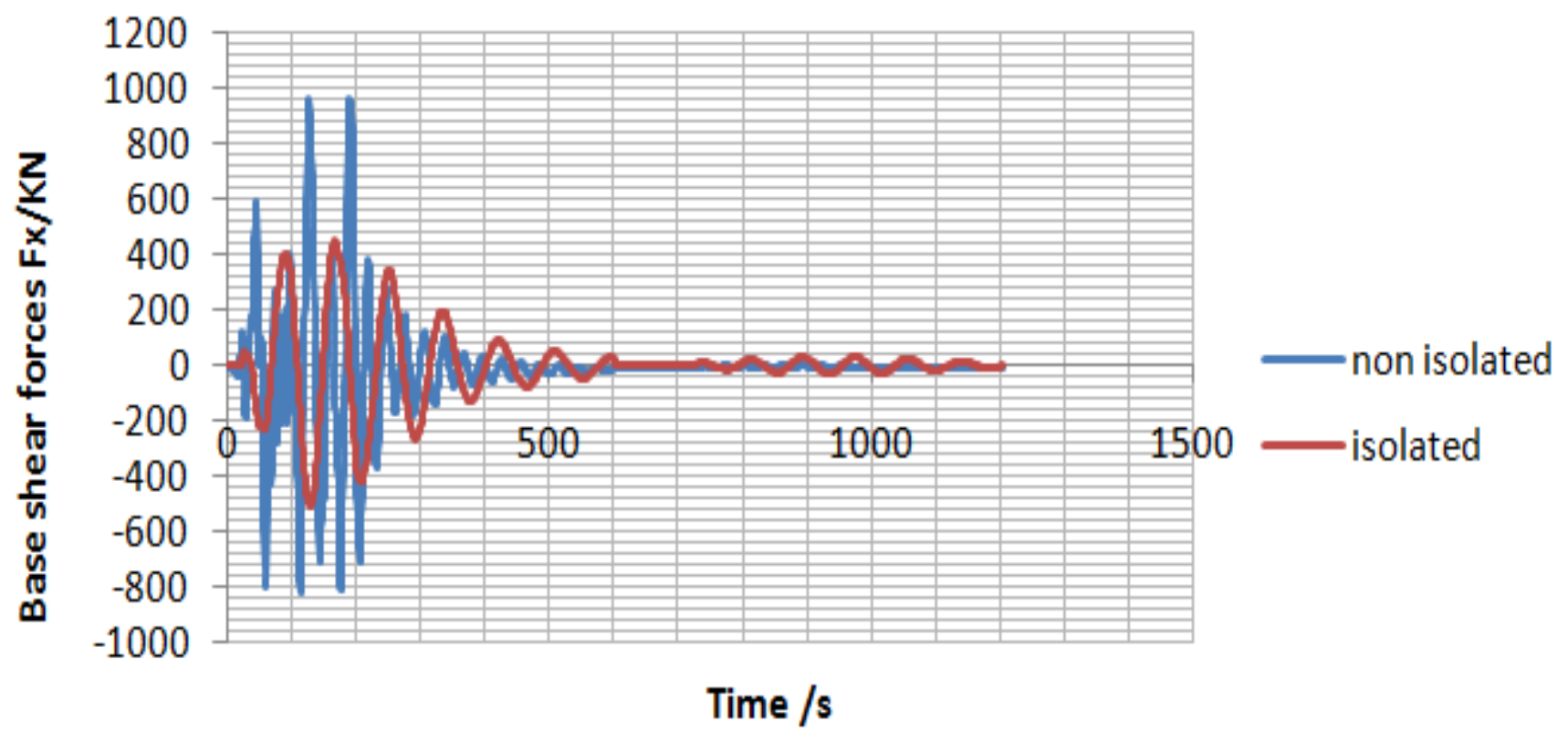

Fig 23: AWR Wave

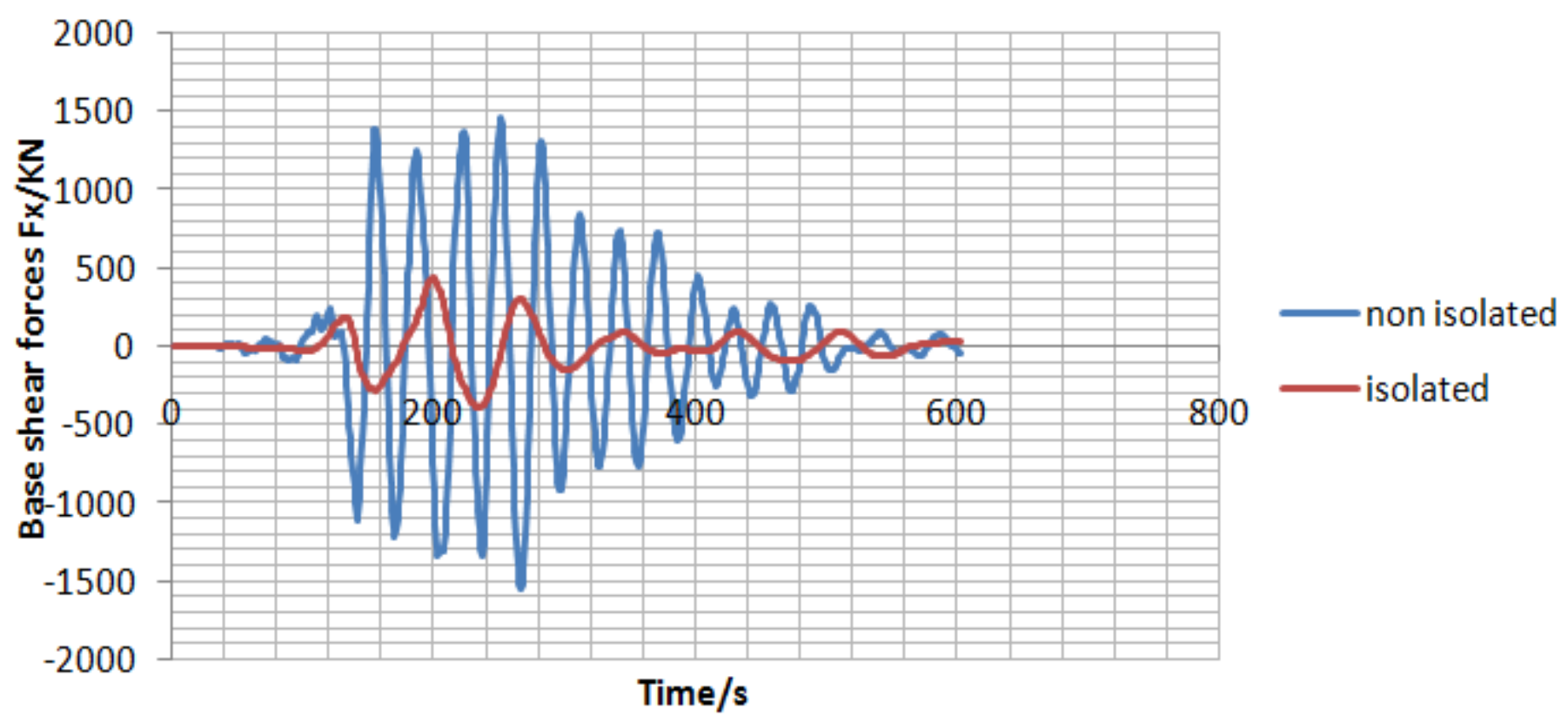

Fig 24: BC Wave

\section{CONCLUSION}

Analysis and comparison of the isolated structure and non isolated structure of their shear forces, acceleration and displacement seismic, found that isolation structure can significantly reduce the shear forces and acceleration and increased displacement. Structures of Seismic response improve the structure seismic fortification level, which proves that the shock absorption effect is good. The use of the base isolators should be selected with a higher model strength parameter isolator in mind, especially if a significant difference is expected in the output of the structural response to the earthquake excitation. 


\section{REFERENCES}

[1]. Shi Wen Huang, Optimal Selection of Reinforcements Methods of Single Span Frame Structure of Primary and Middle School Buildings [M]. Graduate thesis of Southwest Jiao Tong University.

[2]. Rui Jun Zhang, Seismic Performance Research of Base Isolation Frame Structure $[\mathrm{M}]$. Taiyuan University of Technology.

[3]. J. Jothi 2, M. Kavitha3 $\mathrm{T}$,Earthquake Analysis of Structure by Base Isolation Technique in SAP T. [J]. Subramani1,. Subramani et al Int. Journal of Engineering Research and Applications.

[4]. Jian An Hu,Seismic Performance Analysis of Story Isolation with EnergyDissipation Frame Structure, [M]. Anhui University of Architecture .

[5]. Yang Qingtao, The simulation analysis on the Collapse of Isolated Structure [M]. Guangzhou University.

[6]. zhang yu,Chen yao .Li chun-yan, Discussion on the Relation Between Minxian - Zhuoni Earth Quakes in 20032004 and Hydrochemistry, Earthquake Administration of Gansu Province,(Lanzhou7300-China) .

[7]. GB50011-2010, Code for Design of Concrete Structures (in Chinese), Peoples Republic of China

[8]. Okine Macheal ,zhao Jianchang, Mashrah, Seismic Isolation in Strenghening an Existing Retrofitted MasonryReinforced Concrete Building in Huating-China,International Journal of Research in Engineering and Technology eISSN: 2319-1163 | pISSN: 2321-7308.

[9]. GB50010-2010, Code for Design of Concrete Structures (in Chinese), Peoples Republic of China

[10]. PKPM 2010, v2.2, Peoples Republic of China

[11]. G.. Buckle and Lindsay R. Jones, Special Report Seismic Isolation A Solution to the Earthquake Problems of the Precast Concrete Industry Ronald L.Mayes, [J]. Ian .

[12]. Ye Xin Tao Zhong Chen, Analysis of Base Isolation of A Primary School Teaching Building In Kunming

[13]. Yun Ye, The Earthquake Isolation Analysis of Multistory Frame Teaching Building Based SAP2000

[14]. GB50011-2010 Code for Seismic Design of Buildings (in Chinese),Republic of China,2010

[15]. Subramani1, J. Jothi 2, M. Kavitha3T ,Earthquake Analysis of Structure by Base Isolation Technique inSubramani et al Int. Journal of Engineering Research and Applications [M]. ISSN : 2248-9622, Vol. 4, Issue 6( Version 5), June 2014, pp.296-305

[16]. Warn and Keri L. Ryan, A Review of Seismic Isolation for Buildings: Historical Development and Research Needs Gordon P. 2 Buildings[M ]. 2012, 2, 300-325; doi:10.3390/buildings2030300.

[17]. Naeim, F.; Kelly, J.M. Design of Seismic Isolated Structures: From Theory to Practice,[D]. 1st ed.;

John Wiley and Sons: Hoboken, NJ, USA, 1999.

[18]. Sap2000 Ultimate 17.1.1, Build 1099, Computers and Structures Inc., Copyright $\odot$ 1976-2014
[19]. Yun Ye, The Earthquake Isolation Analysis of Multistory Frame Teaching Building Based SAP2000 